\title{
An automated IFC-based workflow for build- ing energy performance simulation with Modelica
}

\author{
Ando Andriamamonjy ${ }^{\mathrm{a}, 1, *}$, Dirk Saelens ${ }^{\mathrm{a}, \mathrm{c}}$, Ralf Klein ${ }^{\mathrm{b}}$ \\ ${ }^{a}$ KU Leuven, Department of Civil Engineering, Building Physics Section, Kasteelpark Arenberg 40 box 2447, BE-3001 Heverlee, Belgium \\ ${ }^{b}$ KU Leuven, Technology Cluster Construction, Technology Campus Ghent, Gebroeders De Smetstraat 1, BE-9000 Ghent, Belgium \\ ${ }^{c}$ EnergyVille, Thor Park 8310, BE-3600 Genk, Belgium
}

\begin{abstract}
Steadily increasing use of Building Information Modelling (BIM) in all phases of building's lifecycle, together with more attention for openBIM and growing software support for the most recent version of the Industry Foundation Classes (IFC 4) have created a very promising context for an even broader application of Building Energy Performance Simulation (BEPS). At the same time, an urgent need for modelling guidelines and standardisation becomes evident. A well-defined BIM-based workflow and a set of tools that fully exploit and extend the possibilities of the openBIM-technology can make the difference when it comes to reliability and cost of BEPS to design, build and operate high-performance buildings. This paper describes the essential elements of this integrated workflow, explains why openBIM comprises much more than just a standardized file-format and what is achieved with the already available technology, namely the Information Delivery Manual (IDM) and a newly developed Model View Definition. This MVD is tailored to the needs of Building Energy Performance Simulation (BEPS) that uses the Modelica language together with a specific library (IDEAS) and can easily be adapted to other libraries. In this project, several tools have been developed to closely integrate BEPS and IFC4. The simulation engine now gets the vast majority of the required input directly from the IFC4-file. For the implementation of the tools, the PYTHON language and the open source library IfcOpenShell are used. A case study is presented, that was used for extensive tests of the proposed approach and the implemented tools. The essential benefits of this new workflow are illustrated, and the feasibility is demonstrated. Opportunities and remaining bottlenecks are identified to encourage further development of BIM software to fully support IFC4 as an information source for BEPS. Beside some improvements of the proprietary class structure and functionality, enabling the export of IFC4 files based on custom MVDs is one required key feature.
\end{abstract}

Keywords: BIM, IFC4, Energy Efficiency, Building Performance Simulation, Building life cycle

\section{Contents}

\section{Introduction}

2 Context and general approach

\section{Modelica library requirements}

\section{BIM to BEPS exchange requirements}

\section{Verification and enrichment}

6 Ifc2Modelica: model generation

6.1 Topology generation $\ldots \ldots \ldots+\cdots$

6.1.1 Nodes . . . . . . . . . . . . . . . 10

6.1.2 Node connectors . . . . . . . . . . . 10

6.1 .3 Edges ................ 11

6.2 Mapping process . . . . . . . . . . 12

6.2.1 Library template . . . . . . . . . . 12

6.2.2 Mapping . . . . . . . . . . 13

\footnotetext{
${ }^{*}$ Corresponding author

Email addresses: ando.andriamamonjy@kuleuven.be (Ando Andriamamonjy), dirk.saelens@kuleuven.be (Dirk Saelens), ralf.klein@kuleuven. be (Ralf Klein)
}

7 Case study 13

7.1 Test facility description . . . . . . . . . . 13

7.2 Scenarios . . . . . . . . . . . . . . 14

7.2.1 Scenario 1............ . 14

7.2 .2 Scenario 2............ 15
8 Discussions

9 Conclusions

\section{Introduction}

Building Energy Performance Simulation (BEPS) models of different detail levels enable to improve building performance and comfort $[1,2]$. Traditional simulation engines such as EnergyPlus [3] or TRNSYS [4] are often used for detailed and transient simulations. However, their lack of modularity and flexibility for prototyping and simulating new technologies have driven the emergence of the modular, equation-based simulation engine: Modelica [5, 6]. Independently of the simulation engine type, BEPS implementation is labor-intensive, timeconsuming and error-prone $[1,7,8]$. A large part of the required 
information could be sourced under certain conditions directly from Building Information Models (BIM).

BIM, an emerging technology [9] in the Architecture Engineering and Construction (AEC) industry, is defined as a digital representation of physical and functional characteristics of a building project $[10,11]$. It is an object-oriented information model incorporating data such as 3D geometry, spatial relationships, geographic information, quantities and building element properties [12-14]. Also, BIM integrates and unifies the communication among stakeholders through a shared, and collective data model, potentially enhancing decision making and work efficiency[11, 12]. Although collaborative, technological and legal challenges need to be addressed [15, 16], BIM adoption has the potential to improve construction coordination, productivity, cost estimate accuracy while reducing clashes (up to $10 \%$ ), omissions, construction time (up to $7 \%$ ) and overall project cost [10, 16-19]. Recently, the use of BIM as an information source for BEPS has gained momentum [1, 8, 20-28]. Three types of solutions can be distinguished:

1. Integration of a simulation engine into the BIM tool or direct coupling using the Application Programming Interface (API) of such software.

2. Export of the relevant information from the BIM tool to a file using the gbXML format and subsequent import of that file into the simulation software. The Green Building XML schema (gbXML) was created for the information transfer from Autodesk REVIT ${ }^{\mathrm{TM}}$ to the online BEPS engine of Green Building Studio. gbXML is a flexible, open, straightforward data schema and was later adopted by several software vendors as a de facto standard for the information transfer from BIM to BEPS [29]. However, the gbXML schema has limited geometry definition capabilities [30, 31] (e.g. only rectangular shapes, based on element centerline) that can lead to an overestimation of the building energy consumption [32].

3. Export of the entire BIM (or preferably the relevant parts of it) to the Industry Foundation Classes (IFC) format $[8,20-22,25,26,28]$ and subsequent import of that file into the simulation software. Developed and maintained by BuildingSMART [33], IFC was officially defined in ISO 16739 and adopted by CEN as EN ISO 16739. Moreover, the BuildingSMART openBIM [33] approach comprises two other important aspects defined in ISO standards: mapping of terms in the form of IFD (International framework for dictionaries, ISO 12006) and IDM (Information Delivery Manual, ISO 29481), a formal process description for the implementation of an openBIM workflow in organizations, for projects and as reference for software certification, based on Model View Definitions (MVDs). Two technical committees (CEN/TC 442 [34] and ISO/TC 59/SC 13 [35]) are actively developing the further standardization of openBIM.

Jeong et al. [23, 24] implemented an example of the solution type 1 , where the Autodesk REVIT ${ }^{\mathrm{TM}}$ API is coupled with the Modelica Buildings library [36]. The lack of interoperability and the dependence on a specific version of a proprietary software constitute the main drawback of this approach.

The second type of solution can be found in commercial software, e.g. DesignBuilder ${ }^{\mathrm{TM}}$ [37] and IES-VE ${ }^{\mathrm{TM}}$ [38] or the open source software tools collection OpenStudio [39], supporting the use of EnergyPlus and Radiance. OpenStudio also partially supports the third type solution by providing IFCimport for some objects of the building envelope.

Most of the third type solutions focus on the geometry representation $[25,40,41]$. One of the early issues was the monolithic description of construction elements (e.g. walls, slabs, ceiling) incompatible with the one-dimensional heat transfer in simulations [22]. Bazjanac et al. addressed this limitation by proposing the space boundary concept $[42,43]$. However, the IFC standard did not include the latter concept correctly before IFC version 4, which led to the development of different space boundary tools [44-46]. Another aspect of the third type solution is the translation of building systems information into BEPS. Bazjanac and Maile [21] designed the IFC HVAC to EnergyPlus utility which can generate an EnergyPlus HVAC input (IDF) from an IFC2x2 and vice versa. However, some information still has to be added manually to obtain a functional IDF file. Later, O'Donnell et al. [47] developed SimModel to tackle the incompatibility between IFC and EnergyPlus input. SimModel is an intermediate data model (currently used in Simergy ${ }^{\mathrm{TM}}$ ) designed to facilitate data exchange for building energy simulation.

Most of the published methodologies solely focus on one specific part of the translation (e.g. geometry or HVAC) and use traditional simulation engines (e.g. EnergyPlus) that require an amount of data only available at the detailed design stage. Bazjanac et al. [7] assessed the use of EnergyPlus at the early design and evaluated the impact of insufficient reliable data that can potentially lead to wrong conclusions. Moreover, the complexity of a detailed BEPS model is not compatible with the need of the operational phase (regarding simulation time), e.g. for Fault Detection and Diagnosis (FDD) or Model Predictive Control (MPC). These examples underline the lack of flexibility of traditional simulation engines and the need for a variable level of detail of the BEPS models for the different life-cycle stages. Expectations concerning the error margins of the results must also be kept realistic. Altogether, these conditions have driven the recent use of the flexible, modular modeling language Modelica for energy simulations.

The successful integration of IFC and Modelica-based BEPS requires a reliable and secure data exchange between BIM and BEPS tools by using guidelines and software certification based on specific MVDs. Pinheiro et al. [48, 49] present a first step addressing this need where they propose an MVD for advanced BEPS. They also identify potential improvements over the current IFC schema release regarding energy simulation.

A significant amount of input data is obtained directly from BIM, but the BEPS expert still needs to take additional decisions and insert new parameters. This task will typically happen in the simulation environment and is subject to the BEPS expert interpretation which can introduce modeling errors [50]. Thereby, the decisions should be documented and communi- 


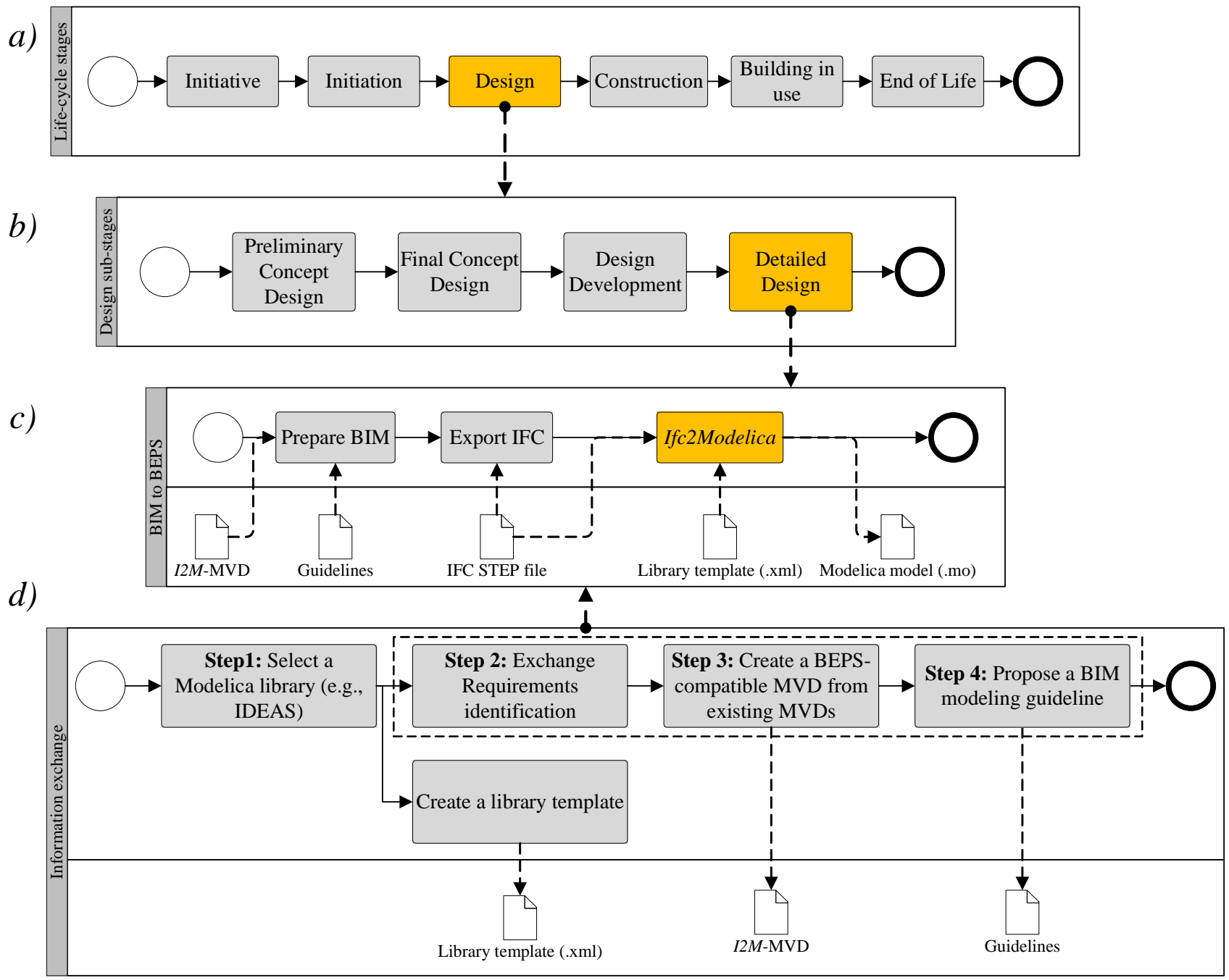

Figure 1: Integration of the proposed workflow throughout the building lifecycle. (a): life-cycle stage of a building, (b): different stages of the design, (c): the proposed BIM to BEPS workflow, (d): Information exchange defining the steps to implement the MVD. (a) and (b) define the stage where the workflow is applied. (c) defines the workflow and (d) how the requirements are implemented.

cated together with the results while a user-friendly BEPS modeling interface would limit the risk of mistakes. Apart from that, the difference between control strategy assumptions during simulations and the proprietary ones implemented in device controllers contributes to the performance gap. Controls are a crucial link between occupancy, climate data, building characteristics and system response, and become increasingly important in reducing energy consumption and peak electrical power demand. Thereby, it is essential to specify controls in BIM to avoid inconsistency between design and operation [6, 51]. Future IFC to (Modelica-)BEPS approaches need to have the capability to translate control representations in BIM into BEPS.

In the frame of IEA Annex 60 activity 1.3, Remmen et al. $[28,52,53]$ have initiated the interfacing of IFC with Modelica. They propose a semi-automated translation of system descriptions encapsulated in IFC into the Modelica library AIXLIB by using SimModel as an intermediate data model [54]. Their methodology relies on the existing IFC into SimModel interface (used in Simergy ${ }^{\mathrm{TM}}$ ) and adds the step to map SimModel into Modelica.

An advantage of using an intermediate data model is the possibility to insert information at this stage that might not be available within IFC. A direct mapping, on the other hand, imposes that IFC incorporates all BEPS-related information (geometry, system, and control) beforehand. The latter approach enables a direct and automated IFC to Modelica translation but requires a more stringent BIM modeling process and a formal data exchange.

The research presented in the current publication investigates the direct translation of BIM to BEPS and proposes an improved workflow that can perform a direct mapping of geometry, system and control representations contained in an IFC4 file to a Modelica-based BEPS model. The flexibility of Modelica facilitates the extension of the workflow to different building life cycle stages with different requirements for model complexity. This work emphasizes the advantages and describes remaining bottlenecks of such a workflow.

The key components of the workflow are: 
1. A BIM guideline and a Model View Definition (MVD, see section 4) ensure that the IFC file incorporates all relevant BEPS information, and allow to automatically check the file's integrity during the exchange process.

2. A novel, PYTHON based IFC to Modelica adapter (hereafter referred to as Ifc2Modelica - section 6) generates the building geometry, the HVAC components and systems and especially the control BEPS model from an IFC file compatible with the proposed BIM guideline. The resulting BEPS model is graphically represented in the user interface of the Modelica simulation engines (e.g. Dymola $^{\mathrm{TM}}$, OpenModelica) to facilitate the integration of simulation related parameters (e.g. type of Air model, solver, initial condition, weather data) typically not (yet) available in BIM.

3. Modelica requirements (section 3) define how Modelica libraries shall be implemented to be compatible with the proposed workflow. These constraints extend the applicability of the workflow to all stages of the entire building lifecycle by implementing libraries which suit the particular needs of each building lifecycle stage.

This workflow is hereafter referred to as BII (BIM-IFCIfc2Modelica). Prior to a more detailed presentation of these components in sections 3 to 6 , section 2 provides an overview of BII and its application for the "detailed design" stage. In section 7, a proof of concept application is presented. The facility of this case study is a university building with two lecture rooms and it is equipped with a variable air volume air handling unit. Two scenarios are considered to emphasize the advantages of BII and to show also remaining limitations, currently preventing a more general adoption.

\section{Context and general approach}

This paper assumes that the involved parties (employer, architects, mechanical engineers, system integrators, manufacturers and facility managers) use an openBIM workflow to manage and exchange information throughout the entire building lifecycle. A distinction is made between information providers (e.g. the architect or a manufacturer) and the BEPS experts, who process the information for energy simulation modeling. IFC4 constitutes the exchange format between the project team members during design and construction, as well as for the asbuilt information transfer to the facility manager and the employer (hand-over).

The information inside BIM evolves throughout the building lifecycle [55] especially during the design stages. In the "preliminary concept design" stage (see figure 1.b), a simplified BIM comprises the building footprint, including the exterior walls with fenestration as a percentage of wall area. In the course of the "final concept design", BIM is enriched with the detailed building elements (e.g. windows, internal walls, floors) and a simplified system description. Later in the "design development" (figure 1.b), BIM incorporates the detailed description of the architectural elements, systems and controls which are subsequently finalized in the "detailed design" stage.
In any of these stages, a BEPS analysis can be conducted [56]. For instance, during the "preliminary concept design" stage, a BEPS enables to identify the different design options. While during the "detailed design" stage, a BEPS model can be used for energy performance certification.

BII applies to the entire building lifecycle but its application will be demonstrated here for the detailed design stage (see figure 1.a and figure 1.b), and the necessary changes for its use in other stages will be described.

BII can generate a Modelica BEPS model compatible with the needs of a specific building life cycle stage. Its use starts with the definition of a Modelica library (see figure 1.d, step 1) that suits the needs of the considered building phase and complies with the constraints defined in section 3. Subsequently, the Information Delivery Manual (IDM, ISO 29481-1:2016 [57]) process is used to identify the data requirements (see figure 1.d, step 2) to implement the BEPS models compatible with the considered building stage (e.g. detailed design stage). IDM deliverables serve as base for a Model View Definition (MVD) (see figure 1.d, step 3), which is a machine-readable (in XMLformat) translation of the requirements and makes it possible to export the exact subset of BEPS-related information. The MVD is used also to ensure a correct IFC file export. Lastly, a set of BIM modeling guidelines (see figure 1.d, step 4) - listing the requirements in a human-readable format - is implemented and should be provided to the design team at the beginning of a project. Section 4 demonstrates how the IDM process, the existing buildingSMART MVDs and the Ifcdoc tool [58] can be used to implement custom MVDs and guidelines, designed for a specific purpose (here: the creation of Modelica models for BEPS at different lifecycle stages).

At any stage of the building lifecycle, the BEPS expert uses the exchanged IFC file as Ifc2Modelica input (see figure 1.c). A verification (and enrichment) of the IFC file is performed to ensure a correct information exchange (section 5). Subsequently, Ifc2Modelica maps IFC to a Modelica BEPS using a Modelica library that is compatible with the needs of that stage (e.g. simplified Modelica library for the early design stage). Section 6 presents the description of the approach behind Ifc2Modelica.

\section{Modelica library requirements}

The present section defines how Modelica components shall be implemented to be compatible with BII. Modelica is a nonproprietary, multi-domain and industry capable modeling language. Modelica models contain differential and algebraic equations, as well as discrete ones. These equations are encapsulated in a Modelica class referred to as Modelica component which provides interfaces (Modelica connectors) enabling interaction with other components. A component is a graphically represented "object" which can be "dragged and dropped" on the user interface of the Modelica simulation engines (e.g. in Dymola $^{\mathrm{TM}}$, OpenModelica). This facilitates model reuse, exchange, and extension by interconnection with other components.

As a modeling principle, a Modelica component preferably represents an actual physical device with the same interface 


\begin{tabular}{ll}
\hline Connectors & Description \\
\hline$\because \because \because \quad \begin{array}{l}\text { Type: } \text { bus connector. Use: Multipurpose } \\
\text { connector used to represent exchanges } \\
\text { between zones and construction compo- } \\
\text { nents. }\end{array}$ \\
$\begin{array}{l}\text { Type: } \text { fluid } \text { connector, Flow direction: } \\
\text { source (left), sink (right), Medium: air } \\
\text { or water. Use: } \text { Enable mass (or fluid) } \\
\text { transfer between components. }\end{array}$ \\
$\begin{array}{l}\text { Type: } \text { heat } \text { connector, Subtype: convec- } \\
\text { tive (left), radiative (right). Use: Enable } \\
\text { heat transfer between components. }\end{array}$ \\
$\begin{array}{l}\text { Type: } \text { signal connector, Flow direc- } \\
\text { tion: source (left), sink (right), Medium: } \\
\text { signal type. Use: Enable control signal } \\
\text { exchanges between control components. }\end{array}$ \\
\hline \hline
\end{tabular}

Table 1: Modelica connectors used in a Modelica library to be compatible with BII

connectors [6]. However, there are no strict rules on how BEPS components need to be defined. As an example, a zone component can either integrate the bounding walls or not; although, Modelica's flexibility allows to adapt one configuration to another depending on the needs.

Moreover, a Modelica connector represents the flow exchange that can occur in reality between the constitutive elements of a building (see table 1 for Modelica connector examples). For instance, one can assume that a zone exchanges air (supply or return) with the HVAC system and exchanges heat (radiative and convective) through the bounding constructions. Hence, a Modelica zone component can have two fluid connectors (input and output) to exchange air, and also heat connectors. There are no standard rules defining the number and type of connectors for a BEPS component.

Considering such flexibility, it is not realistic to implement an IFC to Modelica interface compatible with all possible component configurations. Hence, the following constraints are proposed for the implementation of BII:

1. Connectors: The Modelica Standard Library [59] defines elementary multi-domain connectors that can be used within any Modelica component. Components compatible with BII shall use the connectors described in table 1 for heat and mass transfer as well as signal communication. bus connectors must be used to connect construction components (e.g. walls, windows, slab) with a zone component. heat connectors enable the link between a zone and its internal components; fluid connectors between HVAC components and signal connectors between control com-

\begin{tabular}{l} 
Layout $\quad \begin{array}{l}\text { Connector requirements } \\
\text { nector; and optionally: two opposite flow } \\
\text { fluid connectors, and two heat connec- } \\
\text { tors. }\end{array}$ \\
\hline
\end{tabular}

Construction components must have one
bus connector for external construction,
otherwise two. (non-bus connectors can
be added if necessary).

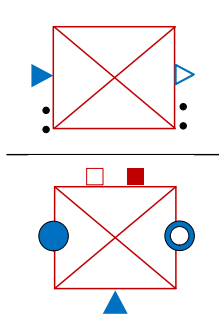

Control components use only signal connectors.

Internal gains and heater components use heat connectors for heat transfer to a zone. A signal connector is added for a controllable component (e.g. ideal heater), fluid connectors are added for radiators.

Table 2: Connector configuration required for Modelica components intended to be compatible with BII

ponents.

2. Components: Components compatible with BII must be defined at the building element level (e.g. a wall is modelled as a separate component) and at the HVAC device level (e.g. dampers, fans, filters). Table 2 shows how zone, construction, HVAC, control and internal gain components must be represented in term of number and type of connectors used. These templates provide the interface definitions (encapsulation) in which equations defining the device are implemented. This makes it possible to extend the use of BII to other lifecycle stages by varying the complexity of the embedded equations to fit into the considered stage.

3. Parameters: Required parameters (e.g. area, volume) need to be defined under the Modelica public statement.

Domain-specific components (e.g. BEPS) are gathered in a Modelica package or library. The IEA EBC Annex 60 library, recently rebranded IBPSA library (IBPSA 1 project), constitutes the core library of the main Modelica libraries dedicated to BEPS: AIXLIB [54], Buildings [36], BuildingSystems [60] and IDEAS [61].

Although any library could be modified to comply with the previous constraints, the building component descriptions in 
IDEAS (see table 3) meet the constraints as mentioned earlier, while both the "Buildings" library and IDEAS satisfy the HVAC and control component requirements. Therefore, IDEAS is used in this study.

IDEAS allows a dynamic simulation of buildings (single or multi zones), systems, controls and also electricity grids as described in Baetens et al. [61]. IDEAS is best suited for the "detailed design" stage, as the amount of information required by the current IDEAS components corresponds to the needs of this stage.

For the "early design" and the "operational" stage, simplified libraries are preferable, since they require less input data and less calculation time.

\section{BIM to BEPS exchange requirements}

This section ensures that the relevant information for energy simulation is included in the BIM and can be reliably exported through IFC later in the process.

Typical problems encountered in a BIM-based energy simulation are:

1. Incomplete product data, incompatible and inaccurate geometry modeling, missing information about zones and spaces,

2. BEPS-incompatible BIM modeling convention. (see [62])

3. Inaccuracy of the information model.

4. Information loss, due to limitations of the BIM software itself, the used project templates or the mapping between proprietary classes and the corresponding IFC classes.

5. Information loss during the IFC export caused by a data scheme, i.e. a Model View Definition (MVD) that is not fully compatible with the needs of BEPS.

6. Incomplete or incorrect HVAC system modeling and missing information about controls.

For a successful use of BIM for energy simulation all concerned parties have to know exactly which information they shall insert into the BIM at a specific point in time of the process. A modelling guideline for BIM shall be provided at the project start to detail such instructions while a BEPS-dedicated MVD can ensure a seamless data exchange between the design team members and the energy simulation tool through IFC. The Information Delivery Manual and Model View Definition (IDM-MVD) methodology allow to define these two key components: a guideline and a MVD (see figure 1.c and figure 1.d).

IDM is an international standard (ISO 29481-1) used to identify the Exchange Requirements (ERs) in a specific process. It ensures that the final information model is semantically meaningful, thus allowing to support the end application (here: BEPS). IDM also specifies when the information from a specific actor in the project is required. A Model View Definition (MVD) translates the previous requirements into a machinereadable format enabling information exchanges between the different software tools in a project.

The IDM-MVD methodology can be implemented by the following steps [48, 63-66].
1. Definition of the overall process as well as roles and functions of the different actors. This step results in a process map presented in a Busing Process Modelling Notation (BPMN).

2. Identification of the exchange requirements (ERs) defining which information to exchange based on use-cases. A use case defines the scope of the process (here: whole building energy simulation models using IDEAS). The ERs are reorganized into Exchange Requirement Models (ERMs) from a set of Exchange Concepts. The latter specifies commonly used (and reusable) packages of information.

3. Implementation of the MVD by representing the ERMs with specific IFC entities (including the IFC version: here IFC4), attributes and types. This means that the Exchange Concepts are translated into MVD concepts.

4. Implementation of a BIM guideline for the end user to comply with the defined ERs.

An MVD consists of a set of MVD concepts that can satisfy the exchange requirements previously set. The latter feature enhances MVDs reusability since concepts in existing MVDs can be analyzed to identify if they meet the exchange requirements for energy simulation. Therefore, MVD concepts defined in official buildingSMART MVDs can be used as building blocks for an energy simulation MVD.

Also, business rules can be applied to an (existing) MVD to adjust its use to a specific application such as energy simulation. They can be applied to constrain the use of specific entities, attributes, properties, and values.

The remainder of this section presents the application of the IDM-MVD approach to formally produce a modeling guideline and MVD compatible with energy simulation using IDEAS. It details how the requirements for an IDEAS-based energy simulation are identified, followed by an approach combining existing MVD concepts with business rules to restructure the requirements into an IDEAS-compatible MVD. At the end of the section the modelling guideline is presented.

Exchange Requirements. This step identifies the requirements for IDEAS-based energy simulation models. This means identifying components, component parameters, and Modelica connections necessary to build an energy simulation model.

Table 3 shows an excerpt of the IDEAS library presenting the zone, window, slab, internal and boundary wall components. An initial step is to identify the required parameters. A zone component requires, at least, its volume, height, n50 value and the number of bounding constructions. A wall needs its azimuth, surface area, orientation, and constructiontype. The constructiontype defines the characteristics of a construction element and must include the number of material layers, their thickness and thermal properties (Thermal conductivity, thermal capacity, density, longwave and shortwave emissivity). Components connectors are then interconnected (see figure 4 as an illustration) to obtain a Modelica model. Walls and windows can only be connected to a zone via the bus connector while ventilation and control system components need to be connected based on actual devices' connections (see figure 9 for illustration). 


IDEAS.Buildings.Components.Zone
(V:volume, hZone:zone height,
n50:infiltration, nSurf:number of bound-
ary surface).

Table 3: Examples of IDEAS library components representing construction elements

The requirements identification was extended to several usecases including single- or multi-zone building models with and without unheated spaces, ideal and hydronic heating systems, Variable Air Volume air conditioning and generic control systems. The models were based on multi-space buildings where a space is a volume enclosed by the surrounding construction elements (walls, windows, roofs, slab), not exchanging air flow through the openings. A thermal zone (modeled as a IDEAS zone component) consists of one or several spaces depending on the building configuration. Thus, a zone component is instantiated using the properties of the aggregated spaces.

Considering system modeling, since IDEAS contains mainly the base system components (e.g. damper, fan, duct components), a ventilation system and especially an AHU must be represented (in BIM) with its constituting elements. This ensures that the methodology is generic and does not depend on the availability of manufacturer specific Modelica components (in IDEAS). Flow direction information ensure that a specific connector of a BIM object is mapped into the corresponding connector in a Modelica component. As an example, if the flow direction of a (BIM) fan object connector (source or sink) is not provided, there is no information to identify which of the object connectors will be mapped into the sink (or source) connector of the Modelica fan component.

MVD implementation. This step identifies and selects among existing MVD concepts those fully or partially fulfilling the exchange requirements. New property sets and business rules are defined if necessary.

This means identifying MVDs that exchange information which can represent zones, HVAC and control components representation, as well as the different properties and connections between the Modelica components.

Among the official buildingSMART MVDs, the IFC 4 Design Transfer View (DTV) satisfies a broad range of exchange requirements varying from coordination planning to visual representation. A comprehensive list of DTV concepts and their definitions can be found in the official IFC4 DTV documentation [67]. These concepts satisfy a large part of the BEPS requirements. For instance, they exchange the required entities (e.g. IfcSpace, IfcZone, subtypes of IfcBuildingElement, subtypes of IfcFlowControlElement and subtypes of IfcControlElement) as well as some parameters (e.g. zone component volume from Qto_SpaceBaseQuantities.GrossVolume). Other parameters result from the combination of different concepts. For instance, walls' azimuth, area and orientation can be computed from the combined information from the Axis 2D Geometry, Product Placement, Body SweptSolid Geometry and space boundary concepts. Connections between building envelop components are retrieved from the space boundary concept while those of the systems and controls result from the port connectivity concept. Since DTV is not a BEPS-specific MVD, additional property sets and business rules are added. As an example, table 4 shows new property sets not defined in DTV but required by IDEAS. Infiltration property $(n 50)$ is attached to IfcSpace entities while parameters describing the glazing performances (SwAbsi, SwAbsDif, SwTrans) are added to IfcWindow entities. Additional property sets could be added if required.

Table 4: Example of an additional property set added to existing MVDs Properties Descriptions

\begin{tabular}{ll}
\hline $\begin{array}{l}\text { IfcSpace } \\
\text { n50 }\end{array}$ & Infiltration value (required by IDEAS) \\
\hline $\begin{array}{l}\text { IfcWindow } \\
\text { SwAbsi }\end{array}$ & $\begin{array}{l}\text { Absorbed solar radiation for each layer as function of } \\
\text { the angle of incidence }\end{array}$ \\
SwAbsDif & $\begin{array}{l}\text { Absorbed solar radiation for each layer as function of } \\
\text { the angle of incidence }\end{array}$ \\
SwTrans & $\begin{array}{l}\text { Transmitted solar radiation as function of the angle of } \\
\text { incidence }\end{array}$ \\
\hline $\begin{array}{l}\text { subtypes of IfcDistributionFlow } \\
\text { fluid }\end{array}$ & Fluid used in the component: air or water \\
\hline $\begin{array}{l}\text { IfcSensor } \\
\text { input type }\end{array}$ & fluid (air or water), heat flow \\
\hline
\end{tabular}

The business rules define constraints for entities, attributes, and properties to adapt the generic DTV concepts to the needs of BEPS. Twelve constraints (see table 5) subdivided into three main parts were added: rules for building geometry, HVAC, and control system. Rules 1 to 4 (table 5) ensures that adjacency relationships (2nd level space boundaries [42]) are exported alongside with the correct construction properties (thickness and layers, material properties). Specifically, rule 4 en- 
ables the definition of the HVAC zoning. Rules 5 to 7 ensure that HVAC systems are correctly described, providing unambiguity for the flow direction within each element of the system. The link between a thermal zone and systems is also clearly defined (Rule 7). Rule 8 to 11 are setting the constraints to establish a control system properly. Rule 12 provides a general constraint for all the property sets that need to be defined.

Finally, the required concepts and entities are combined into a custom MVD referred to hereafter as $I 2 M$ by using IfcDoc [58]. I2M-MVD is then provided to the design team members to ensure seamless data exchange during a project.

Guideline. The requirements set in the Exchange requirements must be translated into a modeling guideline that will be provided to the design team members at the project start. This guideline contains rules that shall be thoroughly applied in order to obtain a BEPS-compatible IFC file. The main rules can be summarized as follow.

1. Geometry description: Spaces must be defined and fully enclosed within constructions. The general guideline presented by Maile et al. [62] can be applied. In addition, spaces belonging to one HVAC zone shall be grouped into one IfcZone entity.

2. HVAC and control description: Equipment and devices constituting HVAC and controls must be (logically) connected following the real devices in the system. Flow and signal directions, as well as devices distribution system, shall be provided (rules 4, 5,6 and 7, table 5), i.e., the flow direction of a BIM object connector must be provided as source or sink.

For Net Zero Energy Buildings, low-energy systems that are capable of bidirectional flow shall be represented in such a way that one of the two possible flow directions is set as the default flow direction in BIM. Since IDEAS components are capable of bidirectional flow, the resulting system model is capable of bidirectional flow, independently of its default flow direction in BIM.

3. AHU description: An air handling unit must be represented by its constituting devices such as dampers, heat recovery or fans (For illustration, see figure 8). This condition is required since IDEAS does not contain entire AHUs, but does contain generic system components from which an AHU model can be built. Also, this condition allows the workflow to be more generic.

4. Actuator: BIM objects representing a controllable device (e.g. Fan, pumps, valves) must be connected to an actuator object (rule 9, table 5). An actuator must be connected to a controller object.

5. Subtype. The BIM object's subtype must be provided. This further identifies the BIM objects having the same type but different subtypes (e.g. a sensor object can have a subtype temperature, $\mathrm{CO}_{2}$, humidity,...).

6. Property set. Standard and custom properties defined in the requirements must be provided.

A similar four-step process can be followed to define the guideline and MVD compatible with other libraries and life cy- cle stages. The guidelines have to be available to the BIM modellers at the beginning of a project alongside with the MVDs. All parties involved have to comply with the guidelines and enter the required information. These specific guidelines can be integrated into a project by using a BIM execution plan as described in the BIM project execution planning guide (CIC-RP) [68] or in PAS 1192 [69].

\section{Verification and enrichment}

BIM-based collaborative design involves different taskspecific tools interoperating through IFC. These tools do not have a uniform IFC4 MVD compliance nor support custom MVDs, increasing the risk of information loss during information exchanges. Therefore, even though the modeling guideline in the previous section is thoroughly applied, data loss might occur during the exchange processes making the resulting IFC file incompatible for energy simulation [70, 71]. In this section a two-step PYTHON based approach is proposed that takes an IFC file as input, performs verification and enrichment to ensure an $I 2 M$-compliant IFC and produces an accordingly modified output IFC file (see figure 2).

Verification. The verification process assesses whether the (IFC) file is fully $I 2 M$-compliant or not. It compares attributes and properties of the entities in the file with $I 2 M$ concepts and business rules (table 5). A non-compliant IFC file will result in a request to enrich the file. At the same time, the developed tool generates a spreadsheet containing the description of the missing information enabling the user to fill the missing values into the corresponding cells before the enrichment process is started.

Enrichment. This process can add semantic information to the IFC file and uses the previous spreadsheet as input to enrich the IFC file with three types of concepts:

1. Object Definition: Property Sets, Quantity Sets

2. Object Association: Material Layer Set, Material Layer Set Usage

3. Connectivity: Port Connectivity, element
connectivity

The ability to instantiate property sets and Material layer makes it possible to update custom and material properties. Similarly, entities that have disconnected ports (If cDistributionPort) are listed and can be connected through this enrichment process by providing in the spreadsheet the port to which the disconnected one shall be attached. An $I 2 M$-compliant IFC file results from this process. It is important to note that this is a temporary step which is introduced to overcome current interoperability limitations. Hoping that those issues will be fixed in future versions of the commercial modelling software, this step can be skipped as soon as a custom MVD (here: $I 2 M$ )can be used directly during the IFC-export of that software. 


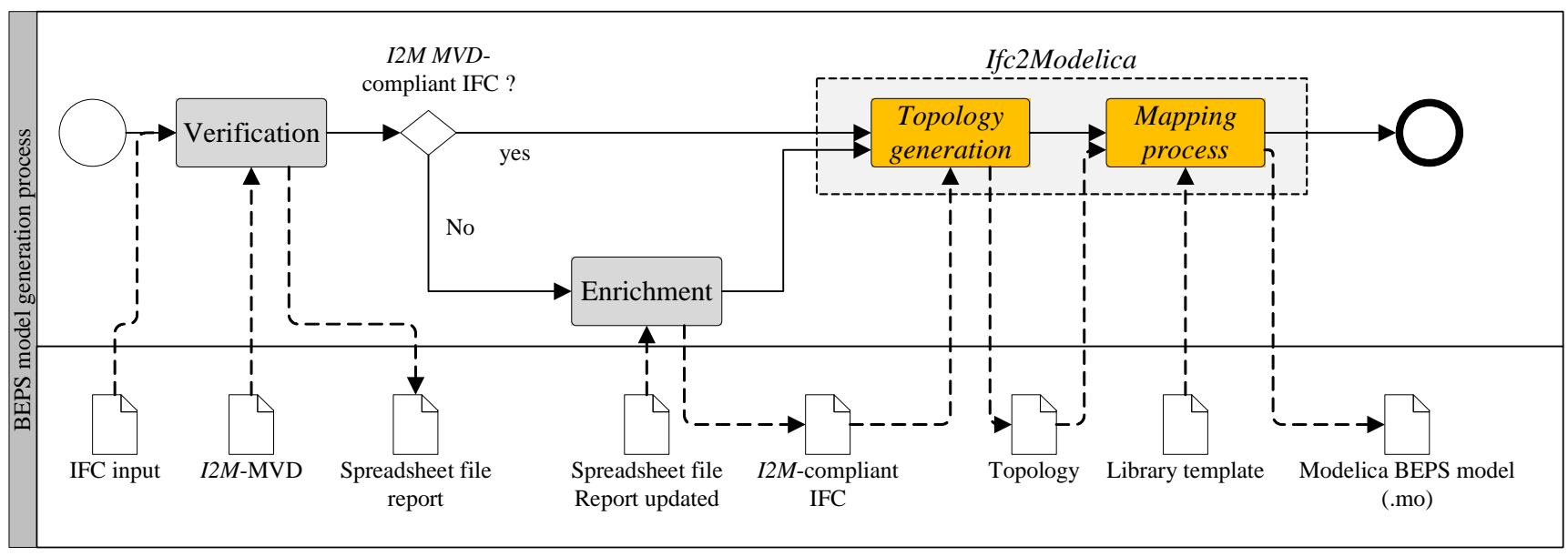

Figure 2: BEPS generation process. Verification and enrichment and direct translation process (Ifc2Modelica).

Table 5: Summary of the business rules defined to tailor standard MVD concepts for energy simulation

\begin{tabular}{|c|c|c|}
\hline Rule Id & Proposition & Allowed value \\
\hline BEPS_Rule_01 & $\begin{array}{l}\text { A construction must be described as a set } \\
\text { of material layers. }\end{array}$ & $\begin{array}{l}\text { IfcRelAssociatesMaterial.RelatingMaterial = IfcMaterialLayer- } \\
\text { Set or IfcMaterialLayerSetUsage or IfcMaterialLayer }\end{array}$ \\
\hline BEPS_Rule_02 & $\begin{array}{l}\text { Material thermal properties must be } \\
\text { provided. }\end{array}$ & $\begin{array}{l}\text { EXISTS IfcMaterialProperties.Properties=TRUE; includ- } \\
\text { ing Pset_MaterialCommon, Pset_MaterialThermal and } \\
\text { Pset_MaterialOptical }\end{array}$ \\
\hline BEPS_Rule_03 & Space boundaries must be defined. & EXISTS IfcSpace.BoundedBy=TRUE \\
\hline BEPS_Rule_04 & $\begin{array}{l}\text { Spaces belonging to the same HVAC zone } \\
\text { must be grouped in a zone. }\end{array}$ & EXISTS IfcSpace. HasAssignments. RelatingGroup = IfcZone \\
\hline BEPS_Rule_05 & Ports must have a specified flow direction. & IfcDistributionPort.FlowDirection=SOURCE or SINK \\
\hline BEPS_Rule_06 & $\begin{array}{l}\text { The distribution system (e.g. Supply air, } \\
\text { return air, exhaust air) to which an object } \\
\text { belongs should be provided. }\end{array}$ & $\begin{array}{l}\text { EXISTS IfcDistributionFlowElement. HasAssignments. Relat- } \\
\text { ingGroup IfcSystem }\end{array}$ \\
\hline BEPS_Rule_07 & $\begin{array}{l}\text { If exists, space heater and air terminals } \\
\text { must be related to a space. }\end{array}$ & $\begin{array}{l}\text { IF EXISTS IfcSpaceHeater, it must be related to an IfcSpace } \\
\text { through the spatial containment concept. IF EXISTS IfcAirTer- } \\
\text { minal, it must be related to an IfcSpace through the spatial } \\
\text { containment concept. }\end{array}$ \\
\hline BEPS_Rule_08 & $\begin{array}{l}\text { A set of sensors (Temperature, } \mathrm{CO}_{2} \text { and } \\
\text { Humidity if required) must be contained } \\
\text { in a space. }\end{array}$ & $\begin{array}{l}\text { IfcSpace.ContainsElement.RelatedElement INCLUDES Ifc- } \\
\text { Sensor. PredefinedType.CO2SENSOR, IfcSensor. Predefined- } \\
\text { Type. TEMPERATURESENSOR, IfcSensor. Predefined- } \\
\text { Type.HUMIDITYSENSOR. }\end{array}$ \\
\hline BEPS_Rule_09 & $\begin{array}{l}\text { An Actuator must be connected to a } \\
\text { controller }\end{array}$ & $\begin{array}{l}\text { IfcActuator must be connected to a IfcController through the } \\
\text { Port Connectivity concept [67]. }\end{array}$ \\
\hline BEPS_Rule_10 & $\begin{array}{l}\text { A controllable HVAC equipment must } \\
\text { host an actuator object. }\end{array}$ & $\begin{array}{l}\text { IfcActuator must be connected to a controllable subtype of } \\
\text { IfcDistributionFlowElement through the Element Connectivity } \\
\text { concept [67]. }\end{array}$ \\
\hline BEPS_Rule_11 & $\begin{array}{l}\text { Type of space heater, sensor, controller } \\
\text { and damper must be provided. }\end{array}$ & $\begin{array}{l}\text { EXISTS IfcSpaceHeater.PredefinedType=TRUE; } \\
\text { EXISTS IfcController.PredefinedType=TRUE; EX- } \\
\text { ISTS IfcSensor.PredefinedType=TRUE; EXISTS Ifc- } \\
\text { Damper.PredefinedType=TRUE. }\end{array}$ \\
\hline BEPS_Rule_12 & $\begin{array}{l}\text { Property set that must be provided (e.g. } \\
\text { table 4) }\end{array}$ & \\
\hline
\end{tabular}

\section{Ifc2Modelica: model generation}

At this stage (see figure 1.c and 2), the IFC file contains all the relevant information for BEPS modeling. The present section details the translation of this IFC file to a Modelica-based energy simulation model using If 2 Modelica. The tool that was developed in this research project uses the PYTHON library IfcOpenShell [72] to handle IFC4 and requires an I2M- compatible IFC and the I2M-MVD (as a .mvdxml) as input. If 2 Modelica consists of two steps: topology generation and mapping process (see figure 2).

The two-space building (space 1 and 2) depicted in fig. 3.a serves as an example to illustrate the process. A thermostat controlled heater conditions the space 1 . For simplicity, only wall 1 and 2 are depicted in the IFC representation of the building in 
figure $3 . \mathrm{b}$ and mentioned in the description hereafter, since all other walls follow the same rules.

\subsection{Topology generation}

A Modelica model structure consists of a set of (1) Modelica components where each component has a set of (2) Modelica connectors. These connectors are then (3) connected to other components' connectors, thus forming a BEPS model.

IFC has a different structure which prevents its direct mapping into Modelica. As an example, the space boundary concept defining the logical connection between a space (IfcSpace) and walls (IfcWallStandardCase) is constituted of several abstract entities, which do not have real physical meanings. A direct mapping implies that each abstract entity is represented as a Modelica component which is both impractical and difficult to implement.

In addition to that, some IFC information is not explicitly available and needs to be computed from a combination of properties and concepts.

The topology generation is a rule based method that transforms the IFC model (e.g. figure 3.b) into a topology (e.g. figure 3.c or figure 3.d) compatible with a direct mapping to a Modelica model (the Modelica library used must comply with the constraints in section 3 ).

The topology consists of three elements: Nodes, Node connectors and Edges. The first two transform IFC entities into objects that mirror Modelica components while the edges represent the Modelica connections.

\subsubsection{Nodes}

A node can be mapped into a Modelica component and is an image of an IFC entity. It has the same attributes, and concepts as the entity it represents. However, based on different criteria presented in this section, the translation from entity to node can be one-to-one, one-to-many or many-to-one.

This section focusses on how IFC data is used to implement the four types of nodes (Zone, Construction, System, and Control).

Zone node. A zone node $(\mathbf{Z})$ corresponds to a Modelica zone component. A zone entity (IfcZone) is translated into a zone node with the characteristics of the aggregated spaces (e.g. space 1 and 2 in fig. 3.b), e.g. the zone volume is equal to the sum of the volumes of all aggregated spaces.

In the case where the spaces (IfcSpace) are not related to a zone, a space entity (IfcSpace) corresponds to a zone node (fig. 3.d). Optionally, for each zone node an occupancy node (O) can be created.

Construction nodes. Construction node types include external $\left(\mathbf{W}_{\mathbf{e}}\right)$ and internal walls $\left(\mathbf{W}_{\mathbf{i}}\right)$, windows (Win) and slabs $(\mathbf{S})$. Each node should correspond to a Modelica component (e.g. in table 3).

As a first translation rule, construction entities (e.g. IfcWallStandardCase, IfcSlab) spanning several spaces are split into several nodes in accordance with the space boundary concept [42]. As an example, wall 1 in fig. 3.a spans space 1 and 2 and is split into five parts. If they are adjacent to an open space (e.g. wall 1-1 and wall 1-2 ), the parts bounding a space are translated into external nodes $\left(\mathbf{W}_{\mathbf{e}}\right)$. Otherwise, they are translated into internal nodes $\left(\mathbf{W}_{\mathbf{i}}\right)$ (e.g. wall 2 ). The distinction between internal and external construction is determined based on the If cRelSpaceBoundary . InternalOrExternalBoundary property and/or by identifying the different overlaping boundary areas computed from IfcRelSpaceBoundary. ConnectionGeometry.

Moreover, slab nodes (S) and window nodes (Win) correspond respectively to: slab entities (Ifcslab) constituting the floor of a space located on the lowest floor and window entities (IfcWindow).

The boundary area (\#A\# in table 3 ) is computed from the IfcRelSpaceBoundary. ConnectionGeometry. Walls and windows are assumed vertical (inclination $=90^{\circ}$.), while their orientation (azimuth) is computed based on the angle between the (true) north and a vector normal to the base surface of the bounded space. This normal vector is computed from the Axis 2D Geometry and Product Placement concepts. Also, slabs are assumed horizontals (inclination $=0^{\circ}$. or $180^{\circ}$.) with an azimuth fixed to zero. Moreover, construction properties come from the Material Layer Set or Material Layer Set Usage concepts. They are formatted into IDEAS specific definitions.

System nodes. The entities that are subtype of the IfcDistributionFlowElement entity are converted into system nodes $\left(\mathbf{S}_{\mathbf{t}}\right)$. $\mathbf{S}$ defines the entity type (e.g. $\mathbf{H}$ for an heater entity, IfcSpaceHeater) and the subscript $\mathbf{t}$ its "predefined type" (e.g. RADIATOR). Therefore, $\left(\mathbf{H}_{\mathbf{R}}\right)$ represents a radiator node.

An exception to the above rule applies to the entities that are a subtype of IfcFlowSegment or IfcFlowFitting entity. These entities are aggregated into one node instance or into the neighboring node instance(s) of the subtype IfcDistributionFlowElement. This will reduce the number of nodes and hereby simplify the energy simulation model.

Control nodes. Control nodes $\left(\mathbf{C}_{\mathbf{t}}\right)$ represent entities that are a subtype of the IfcDistributionControlElement entity. C defines the entity type (e.g. Se for a sensor entity, IfcSensor) and the subscript $\mathbf{t}$ its subtype (e.g. TEMPERATURE). Therefore, $\left(\mathbf{S e}_{\mathbf{T}}\right)$ represents a temperature sensor node.

\subsubsection{Node connectors}

Connectors are additional attributes attached to nodes, derived from the entity type or connectivity concepts. Node connectors represent an analogy to Modelica connectors (see table 1). This section defines four types of connectors (bus, heat, fluid, signal) and details how IFC information is used to attribute these connectors to nodes.

bus connector. It enables heat transfer between zones and construction elements. It is attributed to zone and construction nodes. An internal node $\left(\mathbf{W}_{\mathbf{i}}\right)$ has two bus connectors while other construction nodes and the zone node have only one. 

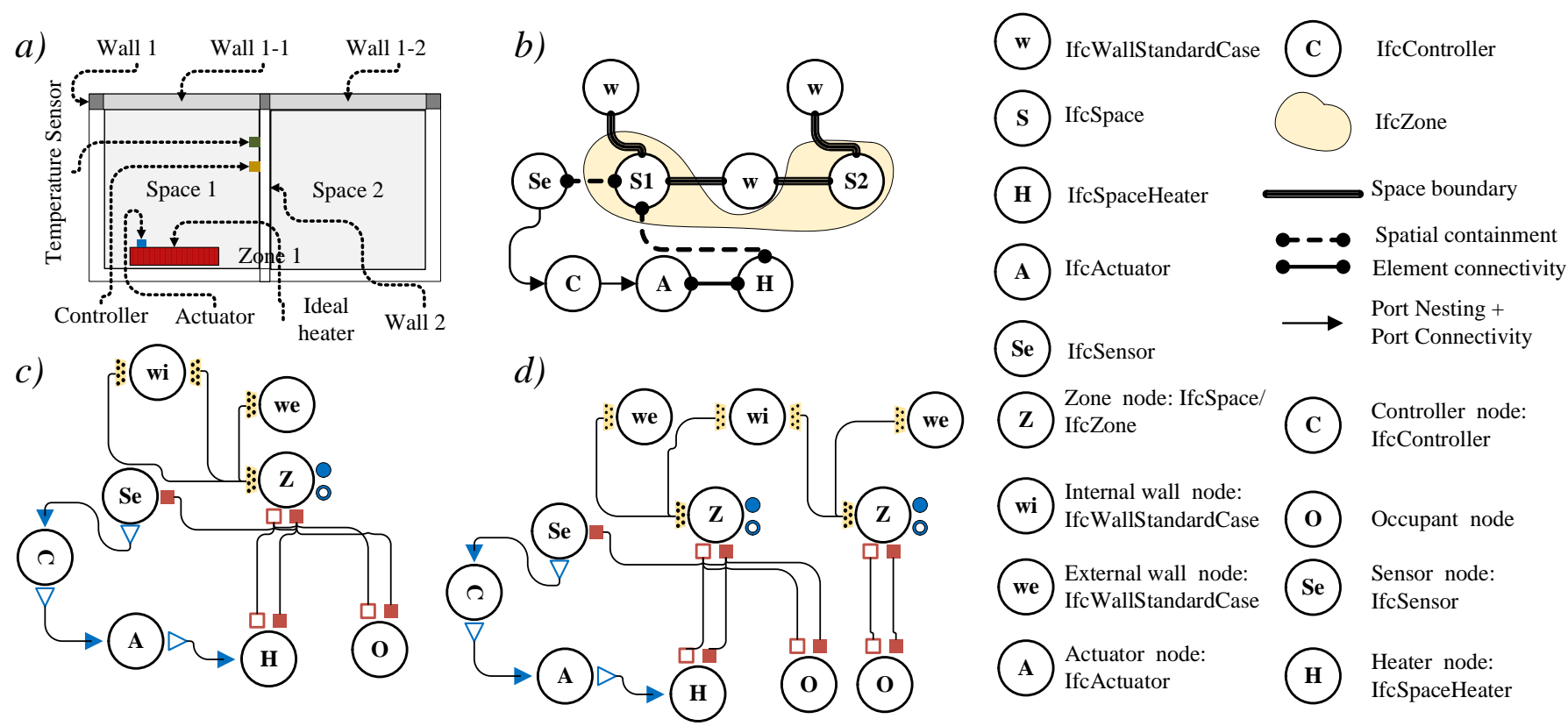

Figure 3: Topology generation process. (a) schematic view of the original BIM. (b) IFC structure of the BIM in (a). (c) Topology generated by Ifc2Modelica where the two spaces are merged. (d) Topology generated by Ifc2Modelica where each space is assumed as a zone.

heat connector. It enables convective and radiative heat transfer between a zone and its "internal components" namely occupants, sensors and heaters (IfcSpaceHeater). Zone, occupant, sensors (heat flow temperature) and heater nodes $(\mathbf{Z})$ have heat connectors.

fluid connector. It enables fluid transfer between building system nodes. A fluid connector is characterized by its flow direction (source or sink), fluid type (e.g. air or water) and a group parameter, e.g. "supply air" or "return air". An additional requirement is, that each fluid connector belonging to the same node must have a unique set of characteristics (e.g. a node with two fluid connectors, both having the same fluid type and flow direction, is not permitted). This will ensure a correct mapping of a fluid connector into a Modelica fluid connector, especially for components with multiple connectors (e.g. heat recovery system).

fluid connectors are attributed to zone and system nodes. A zone node has two fluid connectors with opposite flow direction (source and sink). The number of fluid connectors associated with a system node depends on the number of IfcDistributionPort associated to it. Subsequently, the flow direction is deduced from IfcDistributionPort.FlowDirection while the group to which it belongs originates from IfcDistributionPort.HasAssignments (Group Assignment Concept). The fluid type is either deduced from the entity type (e.g. a node instance representing an IfcAirToAirHeatRecovery entity has air as fluid type) or from the additional property set in table 4 . As an exception to these rules, an air terminal node (IfcAirTerminal) is itself represented as a fluid connector. A fluid (sink) connector is also attributed to a sensor node. signal connector. It enables the exchange of control signals between control system devices. A signal connector is characterized by its signal direction (source or sink) and type (e.g. temperature, $\mathrm{CO}_{2}$, controller). The latter defines the type of signal sent or expected by the connector (e.g. a source-temperature connector sends a temperature signal while a sink-controller connector expects a signal from a specific type of controller).

As a rule, an actuator node (A) has two signal connectors with opposite flow while a sensor node $\left(\mathbf{S e}_{\mathbf{i}}\right)$ has a (source) flow connector. Also, a signal connector is attributed to a controllable system node related to an actuator (element connectivity concept). For the remaining control nodes, the number of signal connectors depends on the number of IfcDistributionPort associated to the node. Connectors flow direction is deduced from IfcDistributionPort.FlowDirection while the type is determined from the node type connected to the port connectivity concept.

\subsubsection{Edges}

The combination of a node and its connectors results in a representation similar to a Modelica component (see figure 3). Edges are the last building block of the topology and represent the Modelica connections, they contain the information about the different pairs of connectors that need to be linked. Thus, the association of those three concepts (node, connector and edge) results in a Modelica compatible topology (e.g. figure 3.c and 3.d).

An edge originates from the conversion of an IFC connectivity concept based on one of the following rules:

1. A space boundary concept, between a zone node and a construction node, links their bus connectors. 


\begin{tabular}{|c|c|c|c|}
\hline Nodes: Entity & Component & Modelica function & Connectors \\
\hline (Z): IfcSpace, IfcZone & 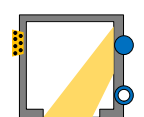 & $\begin{array}{l}\text { function: IDEAS.Buildings.Components.Zone (), in- } \\
\text { put: } \mathrm{V}=\# \text { Gross Volume\#(volume), hzone=\#Height\#(height), n50=\#n50\#, } \\
\text { nsurf=\#nSurf\#(number of adjacent surfaces). }\end{array}$ & $\begin{array}{l}\text { bus, fluid } 1 \text { (air, source), } \\
\text { fluid2(air, sink), } \\
\text { heat(radiative, convective). }\end{array}$ \\
\hline $\begin{array}{l}\mathbf{w}_{\mathbf{i}}: \\
\text { If cWallStandardCase, } \\
\text { IfcSlab, IfcDoor }\end{array}$ & 1 & $\begin{array}{l}\text { function: IDEAS.Buildings.Components.InternalWall(), in- } \\
\text { put:inc=\#inc\#(inclination), azi=\#azi\#(azimuth), A=\#A\#(area), construction- } \\
\text { Type=\#constructionType\#(construction properties). These parameters are internally } \\
\text { computed. }\end{array}$ & bus 1, bus 2 . \\
\hline $\mathbf{w}_{\mathbf{s}}:$ If cSlab & & function: IDEAS.Buildings.Components.SlabOnGround(), input:\#inc\#, \#azi\#, \#A\#. & bus. \\
\hline $\begin{array}{l}\text { We: IfcRoof, } \\
\text { IfcWallStandardCase, } \\
\text { IfcSlab }\end{array}$ & & $\begin{array}{l}\text { function: IDEAS.Buildings.Components.OuterWall(), input:\#inc\#, \#azi\#, \#A\#, } \\
\text { \#constructionType\#. }\end{array}$ & bus. \\
\hline win: If cWindow & & $\begin{array}{l}\text { function:IDEAS.Buildings.Components.Window(), input:\#inc\#, \#azi\#, \#A\#, \#glaz- } \\
\text { ing\#. }\end{array}$ & bus. \\
\hline A: IfcActuator & & function:Modelica.Blocks.Routing.RealPassThrough(). & $\begin{array}{l}\text { signal (source), signal } \\
\text { (sink). }\end{array}$ \\
\hline $\begin{array}{l}\text { (type: } \\
\text { (type } \text { : proportional) }\end{array}$ & $p$ & $\begin{array}{l}\text { function: IDEAS.Controls.Continuous.LimPID, input: } \mathrm{k}=\# \text { ProportionalConstant } \# \text {, } \\
\mathrm{Ti}=\# \text { IntegralConstant }, \mathrm{Td}=\# \text { DerivativeConstant } \# .\end{array}$ & $\begin{array}{l}\text { signal (source), signal } \\
\text { (sink). }\end{array}$ \\
\hline $\begin{array}{l}\mathbf{S}_{\mathbf{T}} \text { : IfcSensor (type: } \\
\text { Temperature, input:heat } \\
\text { flow) }\end{array}$ & $\Omega$ & function: Modelica.Thermal.HeatTransfer.Sensors.TemperatureSensor. & signal (source), heat (sink). \\
\hline $\begin{array}{l}\left.\mathbf{H}_{\mathbf{i}}\right): \text { IfcSpaceHeater } \\
\text { (type: ideal) }\end{array}$ & $\square \square$ & function: User defined. & heat, signal (sink) \\
\hline
\end{tabular}

Table 6: Example of a library template providing the correspondence between Modelica components and nodes. Column 1: correspondence between node and entity. Column 2: Modelica component, column 3: function and input of the Modelica component, column 4: Description of the different connectors attached to the Modelica component.

2. A spatial containment concept, between a zone node and any node with heat connector, links their heat connectors.

3. A spatial containment concept, between a zone node and an air terminal node (or sensor node), links their fluid connectors with opposite flow direction.

4. A port connectivity concept, between any pair of system (or control) nodes, links their fluid (or signal) connectors with opposite flow direction.

5. An element connectivity concept, between a system and a control node, links their signal connectors.

\subsection{Mapping process}

The Mapping process converts a topology into a BEPS Modelica model. However, as a precondition, each node must have a corresponding Modelica component known beforehand. This information is stored in a file hereafter referred to as library template, implemented at the same time as section 4 . As a library template example, Table 6 presents the one used for the example case in figure 3.
The following two sections provide a more detailed description of the library template and the mapping process.

\subsubsection{Library template}

The library template contains a set of component templates which defines the analogy between a Modelica component and a node. A component template contains five fields with information related to the Modelica component: node, function, input, connector and annotation (see table 6).

The "node" field defines which node corresponds to the Modelica component (e.g. table 6, column 1 and 2). The "function" field defines the component path used to instantiate the component, while the "input" field contains the names of the parameters (between \#) that are required to instantiate the component (e.g. table 6 , third column). Those parameters have to be named in accordance with the corresponding property in the (property set) concept. The "connector" field describes the different Modelica connectors attached to the component (e.g. table 6, third column) according to table 1. Especially, it contains the flow direction, fluid type and group of the Modelica 

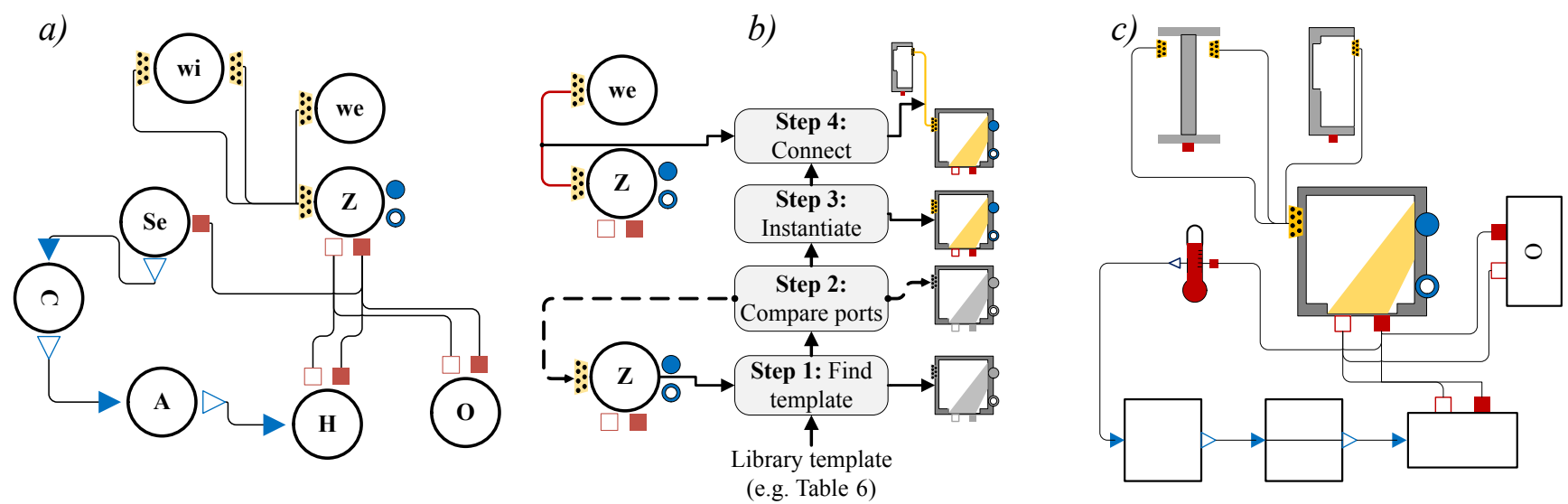

Figure 4: Overview of the mapping process: the translation of a topology (a) into a Modelica BEPS model (c). Step 1: For each node in the topology (a), identification of the corresponding component template in table 6. Step 2: Comparison of the connectors attached to the node with those attached to the component template. Step 3: Instantiation of the components. Step 4: Connection of all the instantiated components, resulting in a Modelica model shown in (c).

fluid connectors. The "annotation" field provides the position information to the Modelica simulation engine for the graphical layout by providing values for $x_{0}, y_{0}, x_{w}$ and $y_{w}$.

\subsubsection{Mapping}

The mapping process instantiates a Modelica component for each node in the topology and converts the edges into Modelica connections (Modelica statement connect). This process consists of four steps: template identification, connector comparison, instantiation and connection (see figure 4).

The template identification searches in the library template (see table 6) the Modelica component corresponding to a node. Example: a zone node $(\mathbf{Z})$ corresponds to the IDEAS. Buildings. Components. Zone component.

The connector comparison identifies whether the identified Modelica component has the same connectors (in terms of type and flow direction) as those defined on the node. If not, the component cannot be instantiated. Then the instantiation retrieves the values of the parameters from the topology, provides a name and instantiates the component. Example: IDEAS. Buildings. Components.Zone zone_1 (nSurf=5, $\mathrm{V}=150$, hZone $=2.7, \mathrm{~A}=55, \mathrm{n} 50=2$ ) annotation

(Placement (transformation (extent $=10,10,25,25))$ ); represents an instance of a zone component. In this step the component is also positioned in the Modelica graphical layout by providing a value to annotation parameters $x_{0}, y_{0}, x_{w}$ and $y_{w}$.

The connection step connects the different instantiated components, using the information contained in the edges. Figure 4 summarizes the mapping process and presents the resulting Modelica model.

\section{Case study}

This section illustrates the benefits of the proposed approach using the developed tools and guidelines (BII). A comparison is made with another BIM to BEPS approach, where the need for a formal information exchange between design representation and BEPS is neglected (ad-hoc BIM to BEPS). To emphasize the advantages of BII, two scenarios are presented in section 7.2. The differences in term of resulting BEPS are underlined and discussed. The building described in section 7.1 is used as a test facility.

\subsection{Test facility description}

The facility, part of the Technology Campus Ghent of KU Leuven (Belgium), is a Near Zero Energy Building (nZEB) and comprises four spaces: the two lecture rooms E120 and E220 (for up to 80 students each), staircase and technical room (see figure 5). The box-shaped rooms (E120 and E220) are thermally insulated not only from the exterior but also from one another and from the staircases. This enables the use of simple uncoupled simulation models, due to the neglectable heat flow in between the different spaces. The external walls of E120 are designed with bricks (high thermal mass) while the external walls of E220 are a timber frame structure (low thermal mass). The two lecture rooms have an identical window area. High performance triple glazing is used and the south oriented windows are equipped with blinds controlled by the BMS. All windows are motorized and can be opened and closed automatically, controlled by the BMS (e.g. to test different night ventilation strategies).

An air handling unit (Menerga ${ }^{\mathrm{TM}}$ AdsSolair 56) ensures the indoor comfort and air quality in E220 and E120. Figure 6 shows the ventilation system scheme including the internal elements of the AHU and the sensors. The AHU is capable of delivering a maximum air flow rate of $5100 \mathrm{~m}^{3} / \mathrm{h}$ and an air flow of $4000 \mathrm{~m}^{3} / \mathrm{h}$ in normal conditions. It has a coefficient of power efficiency of $72 \%$ (EN 13053:2012) and possesses a double heat exchanger (HR in figure 6) in polypropylene and an Indirect Evaporative Cooling (IEC) system. The latter has a cooling capacity of $21.1 \mathrm{~kW}$ and allows a significant cooling (14 K). The heat recovery system can reach an efficiency superior to $75 \%$. The AHU contains two energy-efficient fans (supply air fan: $F N_{S A}$ and return air fan: $F N_{R A}$ ), a supply air filter $\left(F_{S A}, F_{O A}\right)$ and a return air filter $\left(F_{R A}\right)$. Five internal dampers 


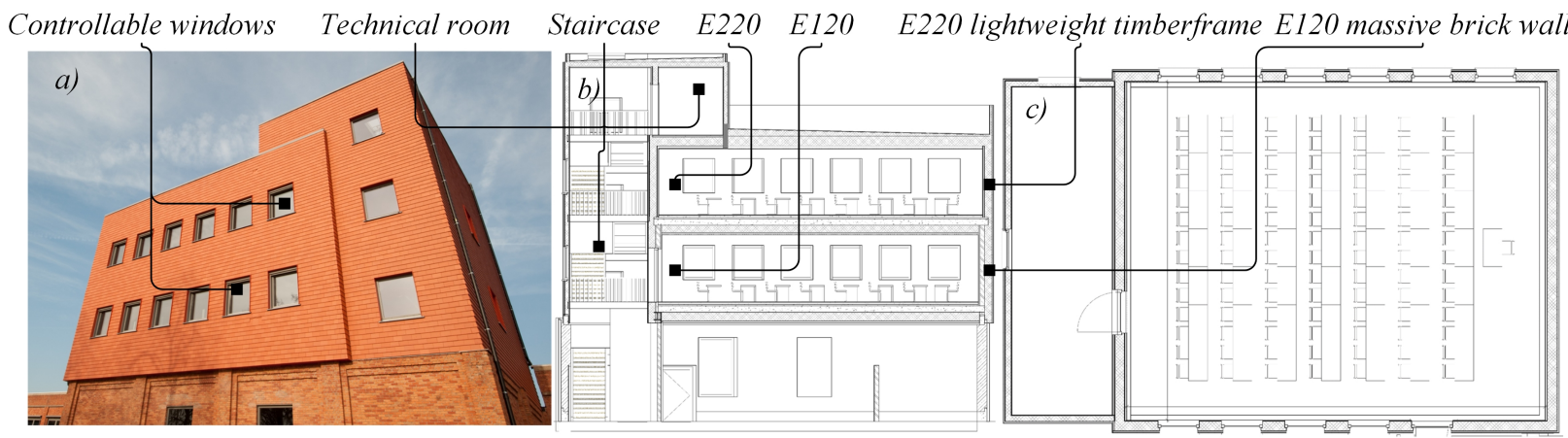

Figure 5: a) Picture showing the southern facade of the facility. b) Section view showing the different spaces (technical room, staircase, E120 and E220). c) Floor plan.

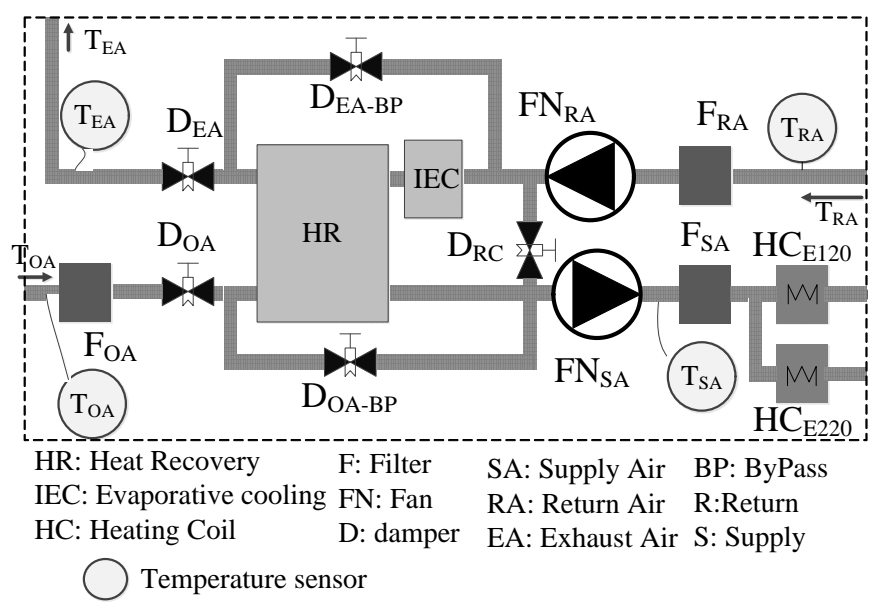

Figure 6: Overview of the components constituting the air handling unit.

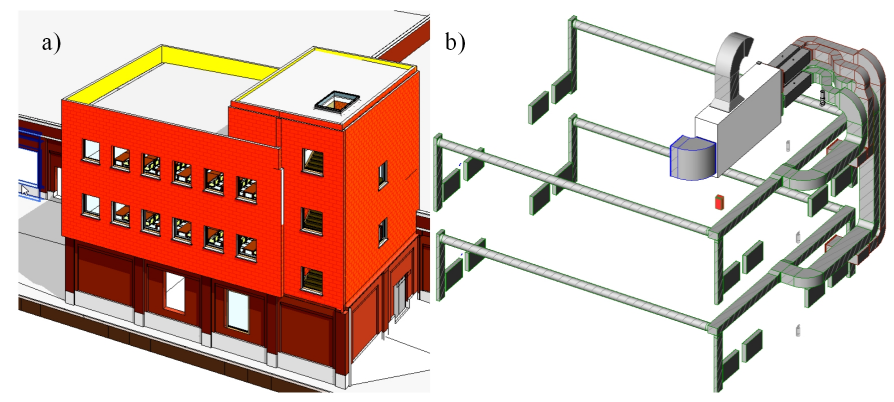

Figure 7: (a) Building envelope representation, (b) Ventilation system representation

(see figure 6): (1) Exhaust Air (EA) bypass $\left(D_{E A-B P}\right)$, (2) exhaust air $\left(D_{E A}\right)$, (3) Outside Air (OA) $\left(D_{O A}\right)$, (4) outside air bypass $\left(D_{O A-B P}\right)$ and $(5)$ recirculation $\left(D_{R C}\right)$ are present. A wood pellet boiler supplies hot water to the heating coils $\left(H C_{E 120}\right.$ and $\left.H C_{E 220}\right)$. Air flow rates to the lecture rooms are regulated by (4) four Variable Air Volume $\left(V A V_{S-E 120}, V A V_{R-E 120}, V A V_{S-E 220}\right.$, $\left.V A V_{R-E 220}\right)$.

The AHU has integrated temperature and humidity sensors placed at the air inlets and outlets and inside the heat recovery system (see figure 6). In addition, temperature (T), humidity $(\mathrm{RH}), \mathrm{CO}_{2}$, Volatile Organic Compound (VOC) and motion de- tection sensors are present in both lecture rooms. Supply and return air volume flow is measured by four venturi tubes equipped with differential pressure sensors.

At hand-over, the HVAC engineer and the architect provided a BIM representing the building envelope and the HVAC system (see figure 7.a and figure 7.b). The models were created before the start of the present study and are not compliant to the guidelines defined in section 4. Also, properties (thermal and physical) and ventilation system descriptions were provided in separated PDF files or spreadsheets and the objects in these models do not contain the required parameter values for BEPS.

\subsection{Scenarios}

Two scenarios are considered to compare the "ad-hoc" BIM to BEPS approach with BII. For both, it is assumed that the project is in the "detailed design" stage. The first scenario considers a BIM implemented without a formal definition of the exchange between design and BEPS, or otherwise said: without prior knowledge of the guideline described in section 4 . The $\mathrm{BIM}$ in figure 7 is directly used as Ifc2Modelica input. The second scenario thoroughly applies BII (including guideline, tools and MVD). An example of BII application alongside with a comparison of the generated models from both situations are provided hereafter.

\subsubsection{Scenario 1}

The BIM in fig. 7.b represents the AHU as a simple box. Its internal component descriptions are provided as data-sheets (or pdf-files) while control strategy information is unavailable. The properties of the building elements are supplied in datasheets and they are not integrated into the BIM. An IFC file is exported from the REVIT ${ }^{\mathrm{TM}}$ model and used as Ifc2Modelica input. The verification process (section 5) checks I2M-MVD compliance and generates a spreadsheet prompting the modeler to input the missing values for the properties (material properties). This manual data transfer increases the risk of errors. Information such as AHU component description and control strategies cannot be inserted through this verification process. Therefore, the BEPS generated from this BIM consists only of the building envelop model described in figure 9.b since there is not enough information to generate the models of the control system and the AHU. 


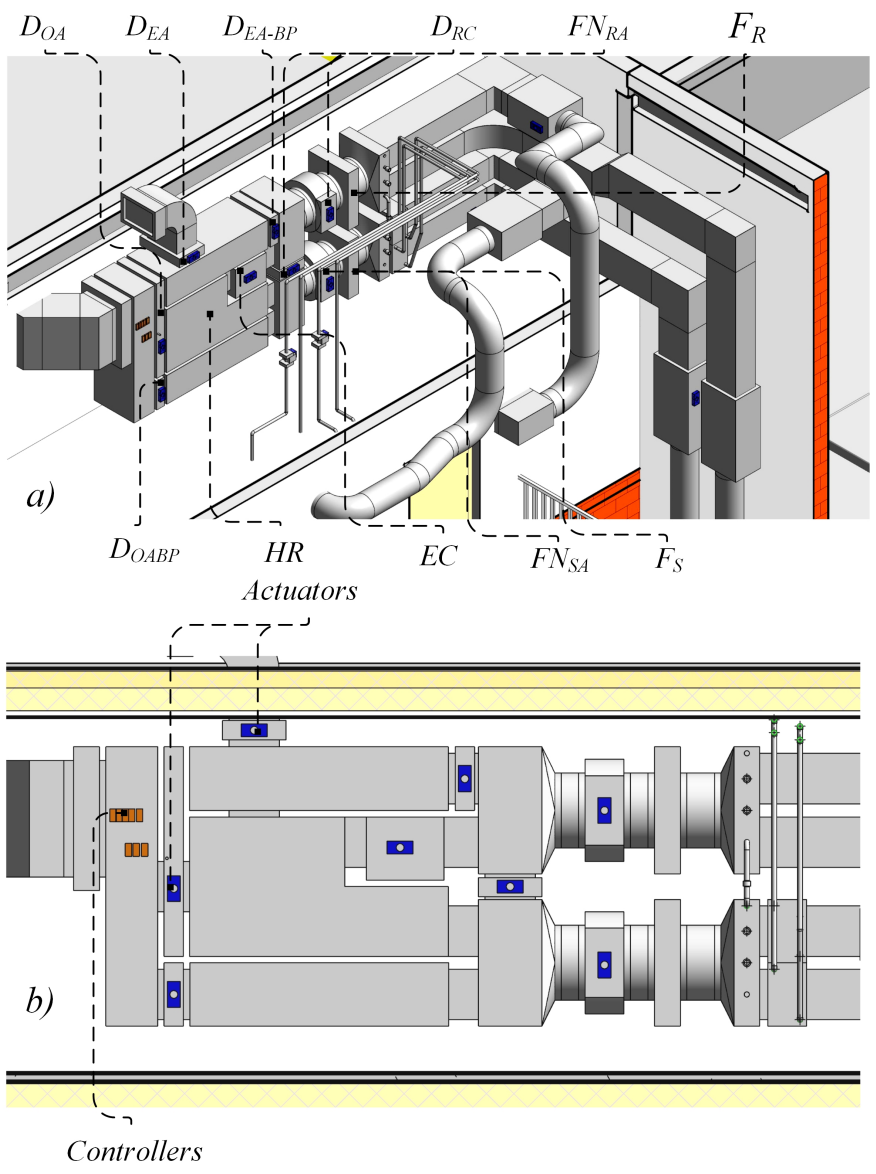

Figure 8: a) Detailed representation of the HVAC system, b) Closer view of the Air Handling Unit representation.

\subsubsection{Scenario 2}

This scenario applies BII using the BIM execution plan proposed in [68] as framework. Energy analysis is defined as one of the BIM uses and the team members have to adhere to the modeling guidelines developed in section 4. More specifically, the AHU must be modeled down to its constituting elements, control strategy information and material properties must be integrated into the BIM. For this scenario to be valid, close collaboration between all involved parties is essential. Ideally, the manufacturers shall provide BIM objects of their products including HVAC control strategies. Often this information is considered as "confidential" and is not provided to the client [5]. The current lack of standardized, open formats further complicates this information exchange. Scenario 2 assumes full cooperation to fulfill the requirements. The different parties shall use IFC4 compatible BIM tools to ensure a seamless data exchange.

Building Information Model. The envelope representation does not visually differ from the original model in figure 7.a since the modifications consist of defining the rooms as IfcSpace objects, and the integration of semantic data such as material properties and property sets (e.g. table 4).

The model for the ventilation system for scenario 2 is shown in figure 8 . In compliance with the requirements defined in sec- tion 4, the AHU and the ductsystem is represented by its constituting elements (e.g. dampers, fans, valves). More specifically, figure 8.b provides a closer view of the AHU model. Such description is obtained by (1) identifying the AHU internal components, brand, type and all relevant characteristics, (2) retrieving or creating the corresponding BIM objects (here: REVIT Family) and (3) assembling and connecting these objects according to the rules 5 to 7 in table 5 and the scheme in figure 6.

Similarly, BIM objects representing actuators (blue boxes in figure 8.a and 8.b) are implemented and attached to controllable devices (fans, dampers, valves) to comply with the rule 10 in table 5 . These actuators are connected to controllers (depicted as brown boxes) (rule 9 in table 5), that send signals to the controllable devices and receive signals from sensors or controllers. As an example, a VAV controller uses the signal from the $\mathrm{CO}_{2}$ and temperature sensors of a lecture room to generate the control signal of the VAV box.

In the following step an IFC4 file is exported. However, due to limitations of the used BIM tool, the direct use of a custom MVD, i.e. I2M-MVD during the export is not yet possible. Instead, the IFC4 Design Transfer View (DTV), in combination with the BIM tool's capability to export user-defined property sets, is used.

BEPS Model. Figure 9 shows the final Modelica BEPS model that was obtained by using the BIM presented in figure 8 as Ifc2Modelica input. The BEPS model comprises the envelope (figure 8.b), the ventilation system (figure 8.a) and the control model (figure 8.c).

It was found that despite the fact that the previously established modelling requirements were met, the connections between controllers and actuators, actuators and system devices were not exported as defined in (rules 7 and 8 in table 5). Also, material properties were missing. These issues are due to the fact that the IFC file was created according to the DTVMVD and some characteristics specific to the I2M-MVD were not exported, thus again emphasizing the need for a custom MVD compatible BIM authoring tool. Also, loss of semantic translation [70, 73] explains why the material properties were not exported. These issues depend on the capabilities of BIM tools to correctly translate proprietary models into IFC4 models. Nonetheless, the newly developed verification tool (see section 5) provides for now a solution allowing to integrate the missing information into the IFC file.

The Model generation process specified in section 6 starts by categorizing entities as nodes or edges according to the rules in sections 6.1.1 and 6.1.3. The topology is mapped into a Modelica BEPS using the library template defined in table 6 and table 7. Table 7 describes the system components whose detailed descriptions and equations are described in IDEAS documentation [74]. In addition, some "user-defined" components are used that are not explicitly defined in IDEAS, but implemented using several components from IDEAS as a base.

Since each room was defined as an IfcSpace and none of them are aggregated in an If cZone, figure 9.b presents the envelope model representing each room (E220, E120, technical 


\begin{tabular}{|c|c|c|c|}
\hline Nodes: Entity & Component & Modelica function & Connectors \\
\hline (T): IfcAirTerminal & & $\begin{array}{l}\text { function: Modelica.Fluid.Interfaces.FluidPort_a() or Model- } \\
\text { ica.Fluid.Interfaces.FluidPort_b(). }\end{array}$ & $\begin{array}{l}\text { fuid (sink) or fluid } \\
\text { (source). }\end{array}$ \\
\hline (D): IfcDamper, IfcValve & & $\begin{array}{l}\text { function: IDEAS.Fluid.Actuators.Valves. TwoWayLinear(), input: } \\
\text { \#m_flow_nominal\#= IfcDamper.NominalAirFlowRate, \#dpValve_nominal\#= } \\
\text { IfcDamper.OpenPressureDrop. }\end{array}$ & $\begin{array}{l}\text { fluid (source), fuid (sink), } \\
\text { signal (sink). }\end{array}$ \\
\hline (F): IfcFan, IfcPump & & $\begin{array}{l}\text { function: IDEAS.Fluid.Movers.FlowControlled_m_flow(), input: } \\
\# \text { \#_flow_nominal\#= IfcFan.NominalAirFlowRate, \#dp_nominal\#= } \\
\text { If cFan.NominalTotalPressure,\#per\# from IfcFan.PressureCurve and } \\
\text { If_Fan.EfficiencyCurve. }\end{array}$ & fluid (source), fuid (sink). \\
\hline $\begin{array}{l}\text { Hr: } \\
\text { IfcAirToAirHeatRecovery, } \\
\text { IfcCoil }\end{array}$ & & $\begin{array}{l}\text { function: IDEAS.Fluid.HeatExchangers.ConstantEffectiveness (), input: \#eps\#= } \\
\text { If cAirToAirHeatRecovery.TotalEffectiveness, \#m1_flow_nominal \#= } \\
\text { IfcAirToAirHeatRecovery.PrimaryAirflowRateRange, \#m2_flow_nominal } \\
\text { \#= IfcAirToAirHeatRecovery.SecondaryAirflowRateRange. }\end{array}$ & $\begin{array}{l}\text { fluid (source, supply air } \\
\text { system), fuid (sink, outside } \\
\text { air system), fluid (source, } \\
\text { exhaust air system), fuid } \\
\text { (sink, return air system). }\end{array}$ \\
\hline (C): IfcEvaporativeCooler & & User-defined. & $\begin{array}{l}\text { fluid (source), fuid (sink), } \\
\text { signal (sink). }\end{array}$ \\
\hline $\begin{array}{l}\text { ( : IfcDuctSegment, } \\
\text { IfcPipe }\end{array}$ & & $\begin{array}{l}\text { function: IDEAS.Fluid.FixedResistances.PressureDrop(), in- } \\
\text { put: \#m_flow_nominal\#=f(Qto_DuctSegmentBaseQuantities, } \\
\text { Pset_DuctSegmentTypeCommon),\#dp_nominal\#= } \\
\text { f(Qto_DuctSegmentBaseQuantities, Pset_DuctSegmentTypeCommon) }\end{array}$ & fluid (source), fuid (sink). \\
\hline (B): IfcBoiler & & User defined. & fluid (source), fuid (sink). \\
\hline
\end{tabular}

Table 7: Additional library template describing the correspondence between system nodes and Modelica components.

room, and staircase) individually as an IDEAS zone component. Figure 9.a and 9.d represent the HVAC system and AHU models respectively. If the AHU had not been designed with its constituting elements, the model in figure 9.d would have been represented by only one Modelica component. This would have required manual modeling of the AHU or the availability of a component describing this specific AHU. However, representing all AHUs on the market as a Modelica component seems unrealistic and the modular approach based on a detailed BIM representation is preferred.

Figure 9.c presents the control system where actuator nodes are converted into "Realpassthrough" components (see IfcActuator in table 6) and serve as a link between controllers and system devices. Controller nodes are mapped into Single-Input Single-output (or Multiple-Input Multiple-output) components (see IfcController in table 6). The IFC4 standard defines five controller subtypes (Floating, Multiposition, Programmable, Proportional, and Two-position) which are then mapped into five different control nodes as described in section 6.1.1. These standardized subtypes are not sufficient to define all existing types of a control system. However, the possibility of establishing user-defined controller types and property sets makes IFC capable of representing any control systems.

\section{Discussions}

Concerning the case study. The contrast between scenario 1 and scenario 2 emphasizes the difference between current practice and a well-coordinated BIM-based workflow (BII). While scenario 1 limits the added value of BII to the envelope model, scenario 2 demonstrates the BIM capabilities to carry BEPSrelated information as well as the capability of BII to generate a complete BEPS model.

However, the collaboration within the design team, called BIM-based Collaboration Network (BbCN) in [15], is key to fulfill the set of requirements in section 4, especially to be able to integrate ventilation and control system data. This partnership creates significant challenges for sharing data and resources, influencing at the same time the decision-making process which involves members of several organizations from different disciplines and backgrounds, likely working in various locations. In addition, legal risks associated with liabilities, BIM intellectual property rights, and managerial difficulties need to be considered. The challenges mentioned earlier are obstacles in harnessing BIM capabilities and constitute an active topic within the research community $[12,15,16]$. As an example, Oraee et al. [15] identify and explore the influential factors towards a successful collaboration while Mignone et al. [75] provide an early solution to address BbCN collaboration issues. 


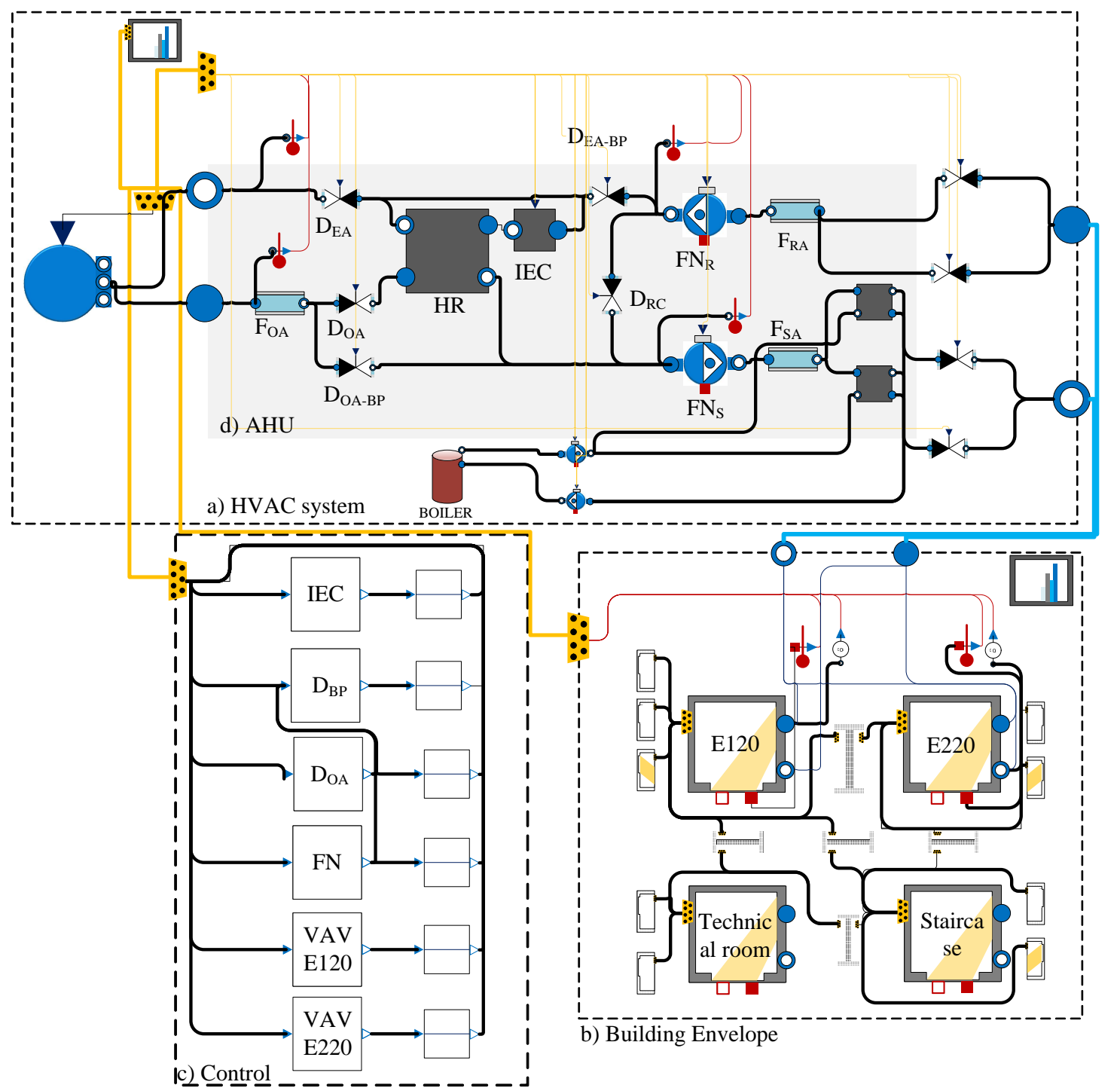

Figure 9: Resulting BEPS Model. a) ventilation system model, b) building envelope, c) Control and d) Air Handling Unit.

In addition to the social collaboration difficulties, technology limitations such as incompatibility of BIM tools with custom MVDs and information loss during object translation currently limit the possibilities of direct BIM to BEPS coupling. These technological issues were already reported in the literature [16] as being among the major obstacles to the full adoption of BIM in general and especially in the translation of BIM to BEPS. In this context, Pinheiro et al. [48, 49] present a first step towards the support of custom MVDs. However, temporary solutions such as the one defined in section 5 are still required while waiting for the necessary improvement of BIM tools.

In scenario 2 , the use of user-defined components emphasizes that a specific library might not include all the appropriate components for a specific device. Existing library components are often based on generic equations and do not embed manufacturer specific features. This emphasizes the importance of online, collaborative modeling processes through a GIT-based platform adopted by some Modelica libraries (e.g. IDEAS and
Buildings). Manufacturers and BEPS experts will then have the opportunity to submit new components or refine existing ones, thus contributing to the fast expansion and growth of such a publicly available library. The constraints presented in section 3 ensure the compatibility of the Modelica components with BII. It can be envisioned in the future to integrate also equations into BIM objects and directly transfer them into Modelica components, using the formal definition of functions as described in the German guideline VDI 3805 [76] and the current drafts of ISO 16757 [77]. This approach is currently under development and depends on the publication of all relevant parts of ISO 16757 to be fully implemented.

General discussion. The resolution of the previously mentioned issues would allow a direct, seamless and fully automated translation from BIM to Modelica-based BEPS models. In such case, BII fits the future view of building energy simulation described by Wetter, in [6], who envisions an "at the press of a button" whole building energy simulation analysis. He also 
emphasizes the need to integrate control strategy specifications into BIM to avoid inconsistencies between design and operation. BII presents a successful attempt to do this. However, as noted in scenario 2, the description of control strategies in IFC needs to be enriched to enable a broader control definition, as already reported by Benndorf et al.[51].

Apart from the previous aspect, BEPS should ideally be open source, user friendly, sufficiently accurate, capable of modeling buildings, HVAC and controls [78]. BII fulfills those conditions since it relies on open-source languages such as PYTHON and Modelica. Free and open BEPS dedicated Modelica libraries include components for modeling electrical, thermal, fluid and control systems. Although BII does not provide a specific user interface, it combines the advantage of a 3D modeling environment (provided by a BIM tool) with the graphical - component oriented - Modelica model representation. The latter facilitates a subsequent modification of the resulting BEPS by manual or "drag and drop" editing of components. Furthermore, since BII connects BIM to a Modelica library, the model accuracy essentially relies on the library's validity. A thorough accuracy assessment of the BEPS model of the case study was already performed but is beyond the scope of this paper and will be published soon. BII is an open BIM to BEPS workflow which fulfills the current needs towards energy efficient building modeling and can be used as a base for the creation of alternatives to commercial BEPS tools.

In this study BII is applied at the "detailed design" stage. Guidelines, MVD and library template compatible with this stage were developed. However, BII is compatible with any other building life cycle stage, necessitating first a thorough application of the exchange process (section 4) to define the guidelines, MVD necessary; as well as the definition of a compatible Modelica library and library template. This process (section 4) is performed only once and need to be updated only when a major modification of the Modelica library occurs. BII can then be applied to any project at the same stage having a similar building and system typology.

\section{Conclusions}

The use of BIM to automate the creation of BEPS models has gained momentum. However, most of the developed methodologies focus on the geometry or system aspects and often rely on additional data sources other than BIM to obtain a functional BEPS model. Most of them are only compatible with the "detailed design" stage.

This paper investigates the direct translation of geometry, system and control representations encapsulated in an IFC4 file into a Modelica-based BEPS model. The applicability of this translation throughout the different life cycle stages is explored by taking advantage of Modelica's flexibility.

To this end, a BIM to BEPS workflow (BII), applicable throughout the entire building lifecycle, was developed. BII defines the constraints for Modelica library components to be compatible with BII at the considered stage. It also includes a formal specification of the data exchange process which provides the essential tools (guideline and MVD) to ensure that the required information is contained in the BIM and correctly exported to IFC. A PYTHON-based tool (Ifc2Modelica) capable of translating the geometry, system and control information contained in IFC into a Modelica-based BEPS was developed. If 2 Modelica generates Modelica models with a convenient graphical layout representation that facilitates modifications of the model.

Two scenarios comparing a typical BIM approach with BII emphasized the advantages of having a formal, machine readable specification of the data exchange and a direct mapping tool. This study demonstrates that the IFC standard, through the possibility to define custom property sets, business rules, and MVDs is flexible enough to carry the information for BEPS modeling. Although improvements will be needed in some areas [48, 51], an IFC4 file can be used as the main data source to automatically and directly translate the contained geometry, system and control representations into a Modelica-based BEPS model. The capabilities of IFC4 combined with the developed direct translation strategy (Ifc2Modelica) and Modelica's flexibility constitute a flexible and adaptable BEPS workflow and enable to avoid switching between several BEPS tools throughout the different stages of the building's lifecycle.

Nonetheless, close collaboration and commitment of all stakeholders are crucial to ensure that the relevant information is integrated correctly into the BIM. Technological challenges, such as the lack of custom MVD support, and limited compliance with IFC4 still restrict to some extend the use of BII. Considering the remaining barriers limiting BII's use, future research should further develop a BEPS-specific strategy that improves the collaboration of all concerned parties.

\section{Acknowledgments}

This project received funding from KU Leuven, the European Union, the European Regional Development Fund ERDF, Flanders Innovation \& Entrepreneurship and the Province of Limburg.

\section{References}

[1] H. Kim, Z. Shen, I. Kim, K. Kim, A. Stumpf, J. Yu, BIM IFC information mapping to building energy analysis ( BEA ) model with manually extended material information, Automation in Construction 68 (2016) 183193. doi:10.1016/j.autcon.2016.04.002.

[2] T. Maile, M. Fischer, V. Bazjanac, Building Energy Performance Simulation Tools - a Life-Cycle and Interoperable Perspective, Tech. rep., CIFE (Center for Integrated Facility Engineering), Civil and Environmental Engineering Dept, Stanford University, Stanford University (2007) [Accessed on: 2018-01-31]. https://stacks.stanford.edu/file/druid:ww813hh4225/ WP107.pdf

[3] D. B. Crawley, L. K. Lawrie, F. C. Winkelmann, W. F. Buhl, Y. J. Huang, C. O. Pedersen, R. K. Strand, R. J. Liesen, D. E. Fisher, M. J. Witte, J. Glazer, EnergyPlus : creating a new-generation building energy simulation program, Energy \& Buildings 33 (2001) 319-331. doi : 10.1016/S0378-7788(00)00114-6.

[4] Thermal Energy System Specialists LLC, TRNSYS, a transient system simulation program [Accessed on: 2018-01-31]. http://www.trnsys.com/ 
[5] M. Wetter, Modelica-based modelling and simulation to support research and development in building energy and control systems, Journal of Building Performance Simulation 2 (2009) 143-161, ISBN: 1940149090281. doi:10.1080/19401490902818259.

[6] J. L. M. Hensen, R. Lamberts, Building performance simulation for design and operation, Spon Press, 2011, ISBN: 9780415474146.

[7] V. Bazjanac, T. Maile, C. Rose, J. O’Donnell, E. Morrissey, B. R. Welle, An assesment of the use of building energy performance simulation in early design, in: 12th International Conference of the International Building Performance Simulation Association (IBPSA), BS2011, no. 1531, 2011 [Accessed on: 2018-01-31]. http://ibpsa.org/proceedings/BS2011/P_1531.pdf

[8] V. Bazjanac, IFC BIM-Based Methodology for Semi- Automated Building Energy Performance Simulation, in: CIB-W78 25th International Conference on Information Technology in Construction, Santiago, Chile July 15-17, 2008, 2008 [Accessed on: 2018-01-31]. https://eetd.lbl.gov/sites/all/files/publications/ $919 e \cdot p d f$

[9] D. Ilter, E. Ergen, BIM for building refurbishment and maintenance: current status and research directions, Structural Survey 33 (3) (2015) 228 256. doi:10.1108/SS-02-2015-0008.

[10] X. Zhao, A scientometric review of global BIM research: Analysis and visualization, Automation in Construction 80 (2017) 37-47. doi:10. 1016/j. autcon.2017.04.002.

[11] T. El-diraby, T. Krijnen, M. Papagelis, BIM-based collaborative design and socio-technical analytics of green buildings, Automation in Construction 82 (2017) 59-74. doi : 10.1016/j . autcon. 2017.06.004.

[12] Y. Liu, S. V. Nederveen, M. Hertogh, Understanding effects of BIM on collaborative design and construction : An empirical study in China, International Journal of Project Management 35 (2017) 686-698. doi : 10.1016/j.ijproman.2016.06.007.

[13] A. Ghaarianhoseini, J. Tookey, A. Ghaarianhoseini, N. Naismith, S. Azhar, O. Emova, K. Raahemifar, Building Information Modelling ( BIM ) uptake: Clear benefits, understanding its implementation, risks and challenges, Renewable and Sustainable Energy Reviews 75 (2017) 1046-1053. doi:10.1016/j.rser.2016.11.083.

[14] H.-y. Chong, C.-y. Lee, X. Wang, A mixed review of the adoption of Building Information Modelling ( BIM ) for sustainability, Journal of Cleaner Production 142 (2017) 4114-4126. doi : 10.1016/j . jclepro. 2016.09.222.

[15] M. Oraee, M. R. Hosseini, E. Papadonikolaki, R. Palliyaguru, M. Arashpour, Collaboration in BIM-based construction networks: A bibliometricqualitative literature review, International Journal of Project Management 35 (7) (2017) 1288-1301. doi:10.1016/j.ijproman.2017.07.001.

[16] C. Sun, S. Jiang, M. J. Skibniewski, Q. Man, A literature review of the factors limiting the application of BIM in the construction industry, Technological and Economic Development of Economy 23 (5) (2017) 764 779. doi:10.3846/20294913.2015.1087071.

[17] D. Bryde, M. Broquetas, J. M. Volm, The project benefits of Building Information Modelling ( BIM ), International Journal of Project Management 31 (7) (2013) 971-980. doi:10.1016/j.ijproman.2012.12. 001.

[18] S. Azhar, Building Information Modeling (BIM): Trends, Benefits, Risks, and Challenges for the AEC Industry, Leadership and Management in Engineering 11 (3) (2011) 241-252. doi:10.1061/(ASCE) LM. $1943-5630.0000127$.

[19] C. Eastman, P. Teicholz, R. Sacks, K. Liston, BIM handbook: A guide to building information modeling for owners, managers, designers, engineers and contractors, John Wiley \& Sons, 2011, ISBN: 111802169X, 9781118021699.

[20] A. Andriamamonjy, R. Klein, D. Saelens, IFC-assisted building energy performance simulation implementation. Development of a python package, in: Proceedings of the 3rd IBPSA-England Conference BSO 2016 Great North Museum, Newcastle, 12th-14th September 2016., no. 1094, 2016 [Accessed on: 2018-01-31]. http://www.ibpsa.org/proceedings/BS02016/p1094.pdf

[21] V. Bazjanac, T. Maile, IFC HVAC interface to EnergyPlus - A case of expanded interoperability for energy simulation, in: IBPSA-USA National Conference, SimBuild 2004, 2004 [Accessed on: 2018-01-31] http://escholarship.org/uc/item/5zb4j9nb

[22] R. J. Hitchcock, J. Wong, Transforming IFC architectural view BIMS for energy simulation, in: 12th Conference of International Building Performance Simulation Association, Sydney, 14-16 November 2011, no. 1391, 2011 [Accessed on: 2018-01-31].

http://www.ibpsa.org/proceedings/BS2011/P_1391.pdf

[23] J. B. Kim, W. Jeong, M. J. Clayton, J. S. Haberl, W. Yan, Developing a physical BIM library for building thermal energy simulation, Automation in Construction 50 (2014) 16-28. doi : 10.1016/j.autcon.2014.10. 011.

[24] W. Jeong, J. B. Kim, M. J. Clayton, J. S. Haberl, W. Yan, Translating Building Information Modeling to Building Energy Modeling Using Model View Definition, The Scientific World Journal (2014) 21.doi : 10.1155/2014/638276

[25] I. J. Ramaji, J. I. Messner, R. M. Leicht, Leveraging Building Information Models in IFC to perform energy analysis in Openstudio, in: ASHRAE and IBPSA-USA SimBuild 2016, 2016 [Accessed on: 2018-01-31]. http://ibpsa-usa.org/index.php/ibpusa/article/view/365

[26] G. Reynders, A. Andriamamonjy, R. Klein, D. Saelens, IFC-Modelica tool facilitating model complexity selection for building energy simulation, in: Proceedings of the 15th International conference of the International Building Performance Simulation Association (IBPSA), BS2017, no. 621, 2017 [Accessed on: 2018-01-31]. http://www.ibpsa.org/proceedings/BS2017/BS2017_621.pdf

[27] V. Dimitriou, S. Firth, T. Hassan, F. Fouchal, BIM enabled building energy modelling : development and verification of a GBXML to IDF conversion method, in: Proceedings of the 3rd IBPSA-England Conference BSO 2016, Great North Museum, Newcastle, 12th-14th September 2016. no. 1126, 2016 [Accessed on: 2018-01-31]. http://www.ibpsa.org/proceedings/BS02016/p1126.pdf

[28] P. Remmen, J. Cao, S. Ebertshäuser, J. Frisch, M. Lauster, T. Maile, D. Müller, C. V. Treeck, An open framework for integrated BIM-based building performance simulation using Modelica, in: 14th International Conference of the International Building Performance Simulation Association (IBPSA), BS2015, no. 2384, 2015 [Accessed on: 2018-01-31]. http://www.ibpsa.org/proceedings/BS2015/p2384.pdf

[29] Y. N. Bahar, C. Pere, J. Landrieu, C. Nicolle, A Thermal Simulation Tool for Building and Its Interoperability through the Building Information Modeling (BIM) Platform, Buildings 3 (2013) 380-398. doi : 10.3390/buildings 3020380 .

[30] Y. Arayici, T. Fernando, V. Munoz, M. Bassanino, Interoperability specification development for integrated BIM use in performance based design, Automation in Construction 85 (2018) 167-181. doi:10.1016/j . autcon.2017.10.018.

[31] B. Dong, K. P. Lam, Y. C. Huang, A comparative study of the IFC and gbXML informational infrastructures for data exchange in computational design support environments Geometry information, in: International Conference of the International Building Performance Simulation Association (IBPSA), BS2007, 2007 [Accessed on: 2018-01-31]. http://www.ibpsa.org/proceedings/BS2007/p363_final.pdf

[32] V. Bazjanac, T. Maile, C. Nytsch-Geusen, Generation of building geometry for energy performance simulation using Modelica, in: Proceedings of the CESBP Central European Symposium on Building Physics / BauSIM 2016, 2016 [Accessed on: 2018-01-31]. http://www.ibpsa.org/proceedings/bausimPapers/2016/ D-01-1.pdf

[33] buildingSMART International, buildingSMART [Accessed on: 2018-0131]. http: //www. buildingsmart.org/

[34] European Committee for Standardization (CEN), CEN/TC 442 - Building Information Modelling (BIM) [Accessed on: 2018-01-31]. https://standards . cen.eu/BP/1991542.pdf

[35] International Organization for Standardization, ISO/TC 59 Buildings and civil engineering works [Accessed on: 2018-01-31]. https://committee.iso.org/home/tc59

[36] M. Wetter, W. Zuo, T. S. Nouidui, X. Pang, Modelica Buildings library, Journal of Building Performance Simulation 7 (4) (2014) 253-270. doi : 10.1080/19401493.2013.765506.

[37] DesignBuilder Software Ltd, DesignBuilder [Accessed on: 2018-01-31]. https://www.designbuilder.co.uk/

[38] Integrated Environmental Solutions, Virtual Environment 2017 [Accessed on: 2018-01-31].

https: //www. iesve.com/VE2017 
[39] NREL (National Renewable Energy Laboratory), OpenStudio [Accessed on: 2018-01-31].

https://www.openstudio.net/

[40] A. Cemesova, C. J. Hopfe, R. S. Mcleod, PassivBIM : Enhancing interoperability between BIM and low energy design software, Automation in Construction 57 (2015) 17-32. doi:10.1016/j.autcon.2015.04. 014.

[41] K.-u. Ahn, Y.-j. Kim, C.-s. Park, I. Kim, K. Lee, BIM interface for full vs . semi-automated building energy simulation, Energy \& Buildings 68 (2014) 671-678. doi :10.1016/j.enbuild.2013.08.063.

[42] V. Bazjanac, Space boundary requirements for modeling of building geometry for energy and other performance simulation, in: Proceedings of the CIB W78 2010: 27th International Conference Cairo, Egypt, 16-18 November [Accessed on: 2018-01-31]. http://www.cibw78.org/conferences/

[43] M. Weise, T. Liebich, R. See, V. Bazjanac, T. Laine, IFC implementation guide: Space boundaries for thermal analysis, Tech. rep., US Government Services Administration (GSA) (2009) [Accessed on: 2018-01-31] http: //www.buildingsmart-tech.org/downloads/ accompanying-documents/agreements/ IFC2x3-space-boundary-implAgreement-2009-09-17.pdf

[44] D. Ladenhauf, K. Battisti, R. Berndt, E. Eggeling, D. W. Fellner, M. Gratzl-michlmair, T. Ullrich, Computational geometry in the context of building information modeling, Energy \& Buildings 115 (2016) 78-84. doi:10.1016/j.enbuild.2015.02.056.

[45] G. N. Lilis, G. I. Giannakis, D. V. Rovas, Automatic generation of secondlevel space boundary topology from IFC geometry inputs, Automation in Construction 76 (2017) 108-124. doi:10.1016/j.autcon.2016.08. 044.

[46] C. M. Rose, V. Bazjanac, An algorithm to generate space boundaries for building energy simulation, Engineering with Computers 31 (2013) 271280. doi : 10.1007/s00366-013-0347-5.

[47] J. O’Donnell, R. See, C. Rose, T. Maile, V. Bazjanac, P. Haves, SIMMODEL: a domain data model for whole building energy simulation, in: 12th International Conference of the International Building Performance Simulation Association (IBPSA), BS2011, no. 1223, 2011 [Accessed on: 2018-01-31].

http://www.ibpsa.org/proceedings/BS2011/P_1223.pdf

[48] S. Pinheiro, J. O’Donnell, R. Wimmer, V. Bazjanac, S. Muhic, T. Maile, J. Frisch, C. Van Treeck, Model View Definition for Advanced Building Energy Performance Simulation, in: Proceedings of the CESBP Central European Symposium on Building Physics / BauSIM 2016, 2016 [Accessed on: 2018-01-31].

http://www.ibpsa.org/proceedings/bausimPapers/2016/ D-02-1.pdf

[49] W. Reinhard, S. Pinheiro, T. Maile, J. O’Donnell, J. Cao, V. Bazjanac, J. Frisch, C. V. Treeck, Improving information exchange between Building Information Modelling (BIM) and Advanced Building Energy Performance Simulation (BEPS), Gebaudetechnik in Wissenschaft \& Praxis 4 (2017) 276-291, ISBN: 2195-643X.

[50] S. Imam, D. A. Coley, I. Walker, The building performance gap: Are modellers literate ?, Building Services Engineering Research \& Technology 38 (3) (2017) 351-375. doi : 10 . 1177/0143624416684641.

[51] G. Benndorf, N. Rehault, M. Clairembault, T. Rist, Describing HVAC controls in IFC Method and application, Energy Procedia 122 (2017) 319-324. doi:10.1016/j.egypro.2017.07.330.

[52] M. Thorade, J. Rädler, P. Remmen, T. Maile, R. Wimmer, J. Cao, M. Lauster, D. Müller, C. Nytsch-geusen, C. Van Treeck, An open toolchain for generating Modelica code from Building Information Models, in: Proceedings of the 11th International Modelica Conference September 21-23, 2015, Versailles, France, 2015. doi:10.3384/ ecp15118383.

[53] R. Wimmer, J. Cao, P. Remmen, T. Maile, J. O. Donnell, J. Frisch, R. Streblow, D. Müller, C. V. Treeck, Implementation of advanced BIM-based mapping rules for automated converions to Modelica, in: 14th International Conference of the International Building Performance Simulation Association (IBPSA), BS2015, no. 2424, 2015 [Accessed on: 2018-0131]. http://www.ibpsa.org/proceedings/BS2015/p2424.pdf

[54] A. Constantin, R. Streblow, D. Muller, The Modelica HouseModels Library: Presentation and Evaluation of a Room Model with the ASHRAE
Standard 140, in: Proceedings of the 10 th International Modelica Conference; March 10-12, 2014, Lund, Sweden, no. 96, 2014, pp. 293-299. doi: 10.3384/ecp14096293.

[55] University of Indiana, USA, BIM Guidelines \& Standards for Architects, Engineers, and Contractors, Tech. rep., University of Indiana, USA (2015) [Accessed on: 2018-01-31].

http://www.iu.edu/ vpcpf/consultant-contractor/ standards/bim-standards.shtml

[56] United States General Services Administration, BIM Guide 05: Energy Performance, Tech. rep. (2015) [Accessed on: 2018-01-31]. www.gsa.gov/bim

[57] International Organization for Standardization, ISO 29481-1: Building information models - Information delivery manual - Part 1: Methodology and format [Accessed on: 2018-01-31]. https://www.iso.org/standard/60553.html

[58] T. Chipman, ifcDoc Tool Summary [Accessed on: 2018-01-31]. http://www.buildingsmart-tech.org/specifications/ specification-tools/ifcdoc-tool

[59] P. Fritzson, Introduction to modeling and simulation of technical and physical systems with Modelica, John Wiley \& Sons., 2011, ISBN: 9781118094259. doi:10.1002/9781118094259.

[60] C. Nytsch-Geusen, J. Huber, M. Ljubijankic, J. Rädler, Modelica BuildingSystems eine Modellbibliothek zur Simulation komplexer energietechnischer Gebäudesysteme, Bauphysik 35 (1) (2013) 21-29. doi : 10.1002/bapi. 201310045.

[61] R. Baetens, R. De Coninck, F. Jorissen, D. Picard, L. Helsen, D. Saelens, OpenIDEAS - An Open Framework for Integrated District Energy Assessment, in: 14th International Conference of the International Building Performance Simulation Association (IBPSA), BS2015, no. 2243, 2015 [Accessed on: 2018-01-31]. http://www.ibpsa.org/proceedings/BS2015/p2243.pdf

[62] T. Maile, J. O'Donnell, V. Bazjanac, C. Rose, BIM Geometry Modelling Guidelines for energy performance simulation, in: 13th International Conference of the International Building Performance Simulation Association (IBPSA), BS2013, no. 1510, 2013 [Accessed on: 2018-0131] http://www.ibpsa.org/proceedings/BS2013/p_1510.pdf

[63] E. El Asmi, S. Robert, D. Mazza, K. Zreik, Multi-physical Model Simulation and Interoperability through BIM/ IFC using COMETH Simulation Engine, in: Architecture, City \& Information Design, EuropIA.14: 14th International conference on the Advances in Design Sciences and Technology, 2014, ISBN: 979-10-90094-18-5.

[64] R. Steinmann, K. Linhard, G. Dangl, G. Calleja-rodriguez, R. Guruz, Collaboration requirements and interoperability fundamentals in BIM based multi-disciplinary building design processes, in: eWork and eBusiness in Architecture, Engineering and Construction: ECPPM, 2016, ISBN: 978$1-315-38690-4$

[65] J. Wix, J. Karlshøj, Information Delivery Manual Guide to Components and Development Methods, Tech. rep., buildingSMART International (2010) [Accessed on: 2018-01-31] http://iug.buildingsmart.org/idms/development/IDMC_ 004_1_2.pdf

[66] I. J. Ramaji, A. M. Memari, Extending the current model view definition standards to support multi-storey modular building projects. , Architectural Engineering and Design Managementdoi:10.1080/17452007. 2017.1386083

[67] T. Liebich, T. Chipman, IFC4 Add1 Specification [Accessed on: 201801-31].

http://www . buildingsmart-tech.org/ifc/IFC4/Add1/html/

[68] CIC-RP (Computer Integrated Construction Research Program), BIM Project Execution Planning Guide version 2.1, Tech. rep., Pennsylvania State Univ., University Park, PA (2011) [Accessed on: 2018-01-31]. http://bim.psu.edu/project/resources/

[69] The British Standards Institution (bsi), Publically Available Specification (PAS) 1192-2: Specification for information management for the capital / delivery phase of construction projects using building information modelling, 2013, ISBN: 9780580826665.

[70] M. Oh, J. Lee, S. Wan, Y. Jeong, Integrated system for BIM-based collaborative design, Automation in Construction 58 (2015) 196-206. doi: $10.1016 / j$.autcon.2015.07.015.

[71] K. Stapleton, B. Gledson, Z. Alwan, Understanding technological inter- 
operability through observations of data leakage in Building Information Modelling (BIM) based transactions, in: Proceedings of the 32nd eCAADe Conference, 10-12 September 2014, Northumbria University, Newcastle Upon Tyne., no. May 2016, 2014 [Accessed on: 2018-01-31]. http://nrl.northumbria.ac.uk/17696/

[72] T. Krijnen, A. Kämäräinen, IfcOpenShell [Accessed on: 2018-01-31]. http://if copenshell.org/python.html

[73] R. Santos, A. A. Costa, A. Grilo, Bibliometric analysis and review of Building Information Modelling literature published between 2005 and 2015, Automation in Construction 80 (2017) 118-136. doi:10.1016/ j. autcon.2017.03.005.

[74] F. Jorissen, R. Baetens, D. Picard, IDEAS v1.0.0 [Accessed on: 2018-0131]. https://github.com/open-ideas/IDEAS

[75] G. Mignone, M. R. Hosseini, N. Chileshe, M. Arashpour, Enhancing collaboration in BIM-based construction networks through organisational discontinuity theory : a case study of the new Royal Adelaide Hospital, Architectural Engineering and Design Management 12 (5) (2016) 333352. doi:10.1080/17452007.2016.1169987.

[76] Verein Deutscher Ingenieure (VDI), VDI 3805-1: Product data exchange in the Building Services - Fundamentals., Tech. rep., Beuth Verlag GmbH, ICS 35.240.99, 97.120. (2011).

[77] International Organization for Standardization (ISO), ISO 16757-2015: Data structures for electronic product catalogues for building services, Tech. rep., ICS 91.010.01. (2015).

[78] E. Atam, Current software barriers to advanced model-based control design for energy-efficient buildings, Renewable and Sustainable Energy Reviews 73 (2017) 1031-1040. doi:10.1016/j.rser.2017.02.015. 